\title{
Numerical Simulation of 30P30N Multi-Element Airfoil Using Delayed Detached-Eddy Simulation
}

\author{
Yao Jin ${ }^{1}$ \\ School of Aeronautics, Northwestern Polytechnical University, Xi'an 710072, China \\ Fei Liao ${ }^{2}$ \\ State Key Laboratory of Nonlinear Mechanics, Institute of Mechanics, Chinese Academy of Sciences, Beijing \\ 100190, China \\ Jinsheng $\mathrm{Cai}^{3}$ \\ School of Aeronautics, Northwestern Polytechnical University, Xi'an 710072, China
}

In this paper, an in-house code based on a cell-centered finite difference method using delayed detached-eddy simulation is employed to investigate the aerodynamic and aeroacoustic characteristics of the 30P30N multi-element high-lift airfoil. The experimental data from the Japan Aerospace Exploration Agency and Floride State University are used to make quantitative comparisons with the calculations. Reasonable agreement is achieved in terms of the statistical quantities, the power spectral density of the pressure fluctuations and the velocity fluctuations in the near flowfield. Additional numerical probes have been introduced to investigate the pressure and velocity spectra in the slat cove, main cove, flap suction side and all the wake regions. The slat cove acts as a shallow cavity where narrow-band peak tones accompanying with low-to-moderate broadband frequencies are captured. Besides, the high-frequency tone at $21 \mathrm{kHz}$ is caused by the slat trailing-edge vortex shedding and the tone at $40 \mathrm{kHz}$ is induced by the main trailing-edge. The spectra around flap component are characteristic by broadband contents due to massive separation on the suction side. Overall, the slat component is considered as a dominant contributor to the noise emission.

\section{Introduction}

When the aircraft noise [1][2] related to the propulsion system is reduced remarkably by the advent of quiet high-bypass turbofan engines [3], the airframe noise [4][5][6] becomes a major contributor to the overall noise emissions especially in taking off or landing configurations. Understanding the underling mechanism will be helpful to promote the corresponding noise reduction concepts and will bring great benefit to the civil aviation industry. To progress the capabilities of numerical techniques for airframe noise prediction, a series of international workshops on the benchmark problems for airframe noise computations (BANC) [7] have been held by the American Institute of Aeronautics and Astronautics (AIAA). Since 2010, five subsequent workshops have already been successfully held, which are the BANC-I in Stockholm in 2010, BANC-II in Colorado in 2012, BANC-III in Atlanta in 2014, BANC-IV in Lyon in 2016 and BANC-V in Atlanta in 2018. Over the past decade, extensive efforts have been

\footnotetext{
${ }^{1}$ Ph.D student, Department of fluid Mechanics, AIAA student. jinyao@mail.nwpu.edu.cn.

${ }^{2}$ Postdoc researcher, State Key Laboratory of Nonlinear Mechanics. 89f.liao@gmail.com.

${ }^{3}$ Professor, Department of fluid Mechanics, AIAA member. caijsh@nwpu.edu.cn.
} 
focused on the following canonical problems: (1) the airfoil trailing-edge noise [8]; (2) the landing gear noise [9]; (3) the slat noise of a multi-element high-lift configuration [10].

In terms of the slat noise, two generic configurations are presented in the workshops: the DLR/ONERA threeelement airfoil [10][11][12] and NASA's modified 30P30N three-element airfoil [13][14][15]. This paper focus on the latter one: modified-30P30N. Two sets of detailed measurements of the flow and acoustic signals are obtained in the wind tunnel facilities at Japan Aerospace Exploration Agency (JAXA) [16][17] and Florida State University (FSU) [18][19][20][21].

Regarding the computational calculations for $30 \mathrm{P} 30 \mathrm{~N}$, majority of the work targets on the mechanism of slat cove. However, less attention is paid on the main and flap components. In the current paper, a detailed numerical investigation on the flow dynamics of the $30 \mathrm{P} 30 \mathrm{~N}$ configuration is carried out where the instantaneous unsteadiness in flowfield, time-averaged statistics and turbulent structures are focused. Apart from the sensors around slat, additional pressure and velocity sensors are placed surrounding the main and flap components so as to provide more quantitative information.

\section{Methodologies}

The compressible Navier-Stokes equations under the curvilinear coordinates are solved:

$$
\frac{\partial \hat{U}}{\partial t}+\frac{\partial \hat{E}}{\partial \xi}+\frac{\partial \hat{F}}{\partial \eta}+\frac{\partial \hat{G}}{\partial \zeta}=\frac{M a}{R e}\left(\frac{\partial \hat{E}_{v}}{\partial \xi}+\frac{\partial \hat{F}_{v}}{\partial \eta}+\frac{\partial \hat{G}_{v}}{\partial \zeta}\right)
$$

where the velocity is normalized by sound speed. Two similarity parameters are Mach number (denoted by $M a$ ) and Reynolds number (denoted by $R e$ ).

$$
\begin{gathered}
M a=\frac{u_{\infty}^{*}}{a_{\infty}^{*}}, \operatorname{Re}=\frac{\rho_{\infty}^{*} u_{\infty}^{*} L^{*}}{\mu_{\infty}^{*}}, \frac{M a}{\operatorname{Re}}=\left(\frac{\rho_{\infty}^{*} a_{\infty}^{*} L^{*}}{\mu_{\infty}^{*}}\right)^{-1}, \quad \rho=\frac{\rho^{*}}{\rho_{\infty}^{*}}, \quad p=\frac{p^{*}}{\rho_{\infty}^{*}\left(a_{\infty}^{*}\right)^{2}}, \quad T=\frac{T^{*}}{T_{\infty}^{*}}, \quad e=\frac{e^{*}}{\left(a_{\infty}^{*}\right)^{2}}, \\
(u, v, w, a)=\frac{\left(u^{*}, v^{*}, w^{*}, a^{*}\right)}{a_{\infty}^{*}}, \quad(x, y, z)=\frac{\left(x^{*}, y^{*}, z^{*}\right)}{L^{*}}, \quad t=\frac{t^{*} a_{\infty}^{*}}{L^{*}},
\end{gathered}
$$

Then the incoming flow variables are:

$$
\rho_{\infty}=1, \quad p_{\infty}=\frac{1}{\gamma}, \quad T_{\infty}=1, \quad e_{\infty}=\frac{1}{\gamma(\gamma-1)}+\frac{M^{2}}{2}, \quad\left(u_{\infty}, v_{\infty}, w_{\infty}, a_{\infty}\right)=(M a, 0,0,1) .
$$

\section{A. High order cell-centered finite difference method}

Simulating turbulence and aeroacoustics requires high-order high-resolution methods. A detailed description of the cell-centered finite difference method (CCFDM) can be found in Refs. [22][23], where the flow-dependent variables (density, velocity, pressure, temperature etc.) are stored on the cell centers and the geometry-dependent variables (geometric coordinates) are stored on nodes, similar to the finite volume formulation. In reality, the 2ndorder cell-centered finite difference method is exactly equivalent to the 2nd-order cell-centered finite volume method [24]. However, the high-order cell-centered finite difference discretization is totally different from the highorder cell-centered finite volume discretization. The high-order CCFDM is highly efficient due to dimensionally-bydimensionally interpolation whist the CCFVM requires expensive Gaussian quadrature integration [25]. Additionally, the satisfaction of geometric conservation law under the curvilinear coordinates is guaranteed through the elaborately designed cell-centered symmetric conservative matrices method [22][23], which targets on the discretization of transformation metrics and Jacobian. 
In this paper, 6th-order optimized linear scheme is used to minimize the numerical dissipation. In terms of the time integration method, the efficiently sub-iterative D3ADI [26] is adopted. 20 sub-iterations are found to give a 4 orders residual reduction.

\section{B. Turbulence methodology}

The Delayed Detached Eddy Simulation (DDES) is utilized for turbulence.

The turbulent viscosity is estimated from the Spalart-Allmaras turbulence model [27], which is given by

$$
\begin{aligned}
& \mu_{t}=f_{v 1} \rho \tilde{v}, \\
& \frac{\partial \tilde{v}}{\partial t}+u_{j} \frac{\partial \tilde{v}}{\partial x_{j}}=\frac{1+c_{b 2}}{\sigma}\left[\frac{\partial}{\partial x_{j}}\left((v+\tilde{v}) \frac{\partial \tilde{v}}{\partial x_{j}}\right)\right]-\frac{c_{b 2}}{\sigma}(v+\tilde{v})\left(\frac{\partial \tilde{v}}{\partial x_{j}}\right)^{2}+c_{b 1}\left(1-f_{t 2}\right) \tilde{S} \tilde{v}-\left(c_{w 1} f_{w}-\frac{c_{b 1}}{\kappa^{2}} f_{t 2}\right)\left(\frac{\tilde{v}}{d_{w}}\right)^{2},
\end{aligned}
$$

where $d_{w}$ is the minimum distance to the wall. The principle of Detached Eddy Simulation (DES) [28] is to replace $d_{w}$ with a grid-related scale:

$$
d_{D E S}=\min \left(d_{w}, C_{D E S} \Delta_{\max }\right),
$$

where $\Delta_{\max }=\max \left(\Delta_{x}, \Delta_{y}, \Delta_{z}\right)$ and $C_{D E S}=0.65$. To remedy the grid-induced separation (GIS) in DES, a new length scale is further given to replace $d_{D E S}$ with the modified $d_{D D E S}$ :

$$
\begin{aligned}
& d_{D D E S}=d_{w}-f_{d} \max \left(0, d_{w}-C_{D E S} \Delta_{\max }\right), \\
& f_{d}=1-\tanh \left(\left(8 r_{d}\right)^{3}\right), \\
& r_{\mathrm{d}} \equiv \frac{v_{t}+v}{\sqrt{U_{i, j} U_{i, j}} \kappa^{2} d_{w}^{2}},
\end{aligned}
$$

which is called Delayed DES (DDES) [29]. A further modification in this paper to promote the shear-layer instability development comes from Chauvet et al. [30]:

$$
\Delta_{\omega}=\sqrt{\left(\frac{\omega_{x}}{|\vec{\omega}|}\right)^{2} \Delta y \Delta z+\left(\frac{\omega_{y}}{|\vec{\omega}|}\right)^{2} \Delta z \Delta x+\left(\frac{\omega_{z}}{|\vec{\omega}|}\right)^{2} \Delta x \Delta y},
$$

where $\omega_{x} /|\vec{\omega}|, \omega_{y} /|\vec{\omega}|$ and $\omega_{z} /|\vec{\omega}|$ represents the vorticity along three directions.

\section{Benchmark validation}

Firstly, a benchmark tandem cylinder [31][32][33][34][35] is given as validation to demonstrate the feasibility of the in-house code and the capability of DDES in resolving unsteady turbulent scales. The diameter of circular cylinder is $D=0.05715 \mathrm{~m}$. The spacing is $L / D=3.7$. The spanwise length is $3 D$. The Mach number is $M a=0.128$ and Reynolds number based on the diameter of cylinder is 1.66e5. Fig. 1 shows the instantaneous isosurface colored by the streamwise velocity. Fig. 2 and Fig. 3 show good quantitative comparison with the experimental data.

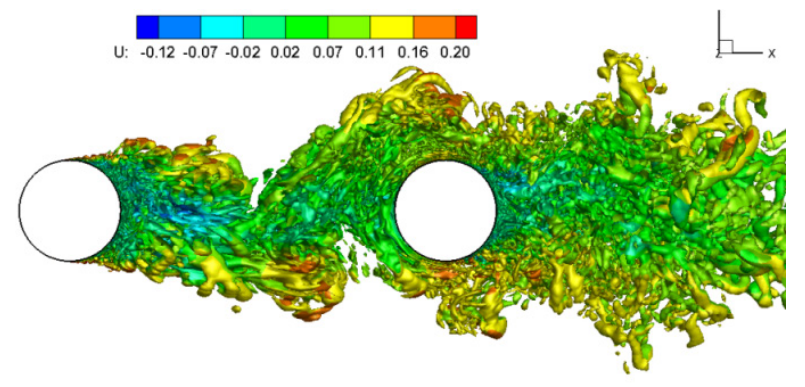

Fig. 1 Isosurface of Q-criterion colored by the streamwise velocity. 


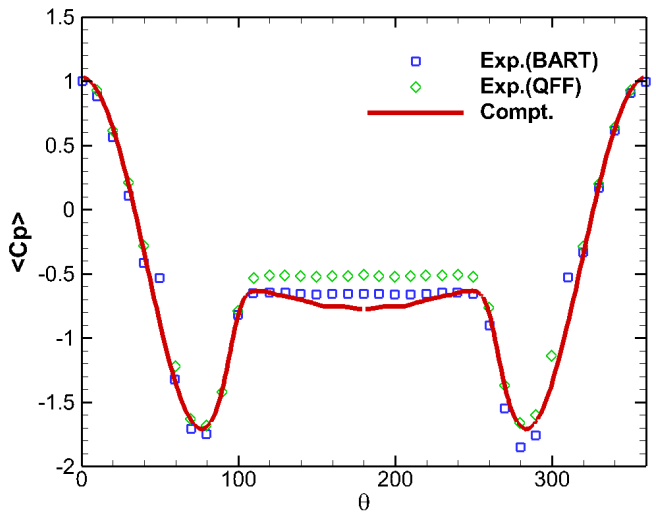

(a) Upstream cylinder

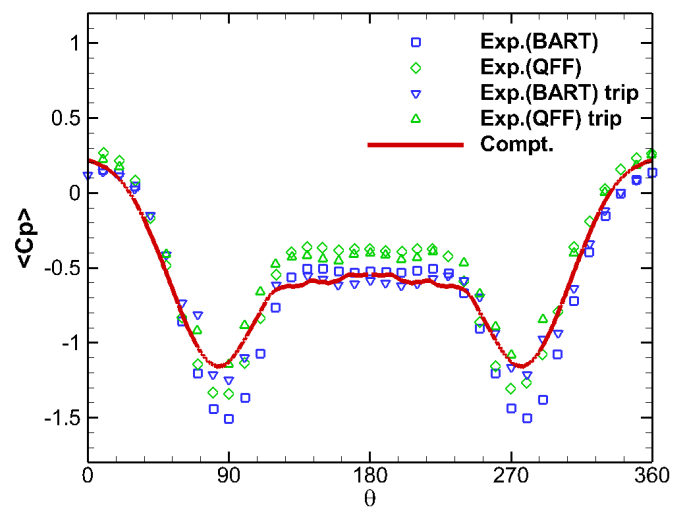

(b) Downstream cylinder

Fig. 2 Time averaged pressure coefficient on the cylinder surface.

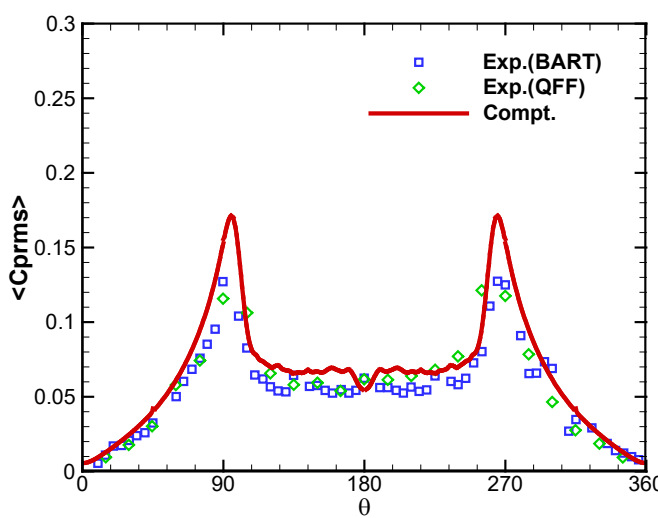

(a) Upstream cylinder

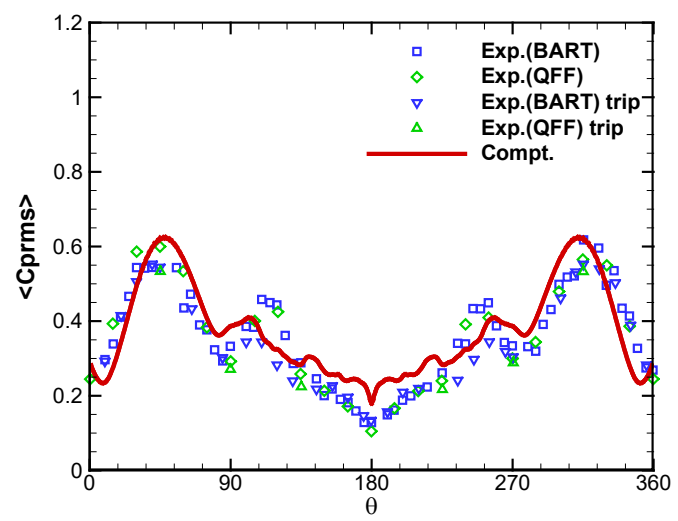

(b) Downstream cylinder

Fig. 3 Root-mean-square pressure coefficient on the cylinder surface.

\section{Numerical results of 30P30N}

\section{A. Modified 30P30N airfoil configuration}

30P30N configuration, designed by McDonnell-Douglas (now Boeing), consists of three elements, slat, main and flap, where the slat and flap elements are deflected 30 degree relative to the main element chord. The stowed aerodynamic chord is $C=0.457 \mathrm{~m}$ (18 inch), slat chord and flap chord are $0.15 \mathrm{C}(0.0685 \mathrm{~m})$ and $0.3 C(0.1371 \mathrm{~m})$ respectively. Both slat and flap are deflected $30^{\circ}$ to the stowed position. To incorporate the unsteady pressure transducers, the slat trailing-edge is modified to be slightly thicker $(0.762 \mathrm{~mm})$ than the unmodified one for the BANC workshops. This modification will incur a very high frequency tone.

The incoming Mach number is 0.17 and the Reynolds number based on the stowed aerodynamic chord is 1.7 million. The angle of attack is 5.5 degree. Tab. 1 shows more detailed info about the modified $30 \mathrm{P} 30 \mathrm{~N}$ configuration. The definition of geometric parameters, slat deflection, gap and overlap relative to the nearest element, are given in the doctoral dissertation by Pascioni [36]. In addition, the related numerical publications on the modified-30P30N are summarized in Tab. 2. 
Tab. 1 Parameters for the modified 30P30N

\begin{tabular}{cccc}
\hline \hline info & parameters & info & parameters \\
\hline Stowed chord length & $C=0.457 m$ & - & - \\
Slat deflection angle & $30^{\circ}$ & Chord of slat & $C s=0.15 \mathrm{C}$ \\
Flap deflection angle & $30^{\circ}$ & Chord of flap & $C f=0.3 \mathrm{C}$ \\
Slat gap & $G_{s}=2.95 \%$ & Flap gap & $G s=1.27 \%$ \\
Slat overhang & $O_{s}=-2.5 \%$ & Flap overhang & $O_{f}=0.25 \%$ \\
Slat leading thickness & $0 m$ & Slat trailing thickness & $0.001668 \mathrm{C}(0.762 \mathrm{~mm})$ \\
$M a$ & 0.17 & Re & 1.7 million \\
Angle of attack & $5.5^{\circ}$ & Span-length & $0.0508 m(0.74 \mathrm{Cs})$ \\
\hline \hline
\end{tabular}

Tab. 2 The available numerical studies on modified-30P30N.

\begin{tabular}{|c|c|c|c|c|c|c|c|}
\hline Authors & Year & Method & Grid (Code) & Cells, $\times 10^{6}$ & Span cells & $\begin{array}{c}\text { Time span, } \\
T U_{\infty} / C \\
\end{array}$ & $\begin{array}{c}\text { Time step, } \\
\Delta t U_{\infty} / C \\
\end{array}$ \\
\hline Lockard \& Choudhari [37] & 2011 & $\begin{array}{l}\text { Comp. } \\
\text { DDES }\end{array}$ & $\begin{array}{c}\text { Str. } \\
\text { (CFL3D) }\end{array}$ & 62 & 129 & 10.92 & $2.8 \times 10^{-4}$ \\
\hline Locard et al. [38] & 2014 & $\begin{array}{l}\text { Comp. } \\
\text { ILES }\end{array}$ & $\begin{array}{l}\text { Str. (CFL3D \& } \\
\text { OVERFLOW) }\end{array}$ & $\begin{array}{c}62 \\
73.2\end{array}$ & 129 & 8 & $2.76 \times 10^{-4}$ \\
\hline Terracol et al. [39] & 2015 & $\begin{array}{c}\text { Comp. } \\
\text { DDES/ZDES }\end{array}$ & Str. & 73.6 & 271 & 10 & $2.7 \times 10^{-5}$ \\
\hline Ashto et al.[40] & 2016 & $\begin{array}{c}\text { Comp. } \\
\text { SST-IDDES }\end{array}$ & $\begin{array}{c}\text { Unstr. } \\
\text { (STAR-CCM+) }\end{array}$ & 73.6 & 271 & 7 & $1.46 \times 10^{-4}$ \\
\hline Zhang et al.[41] & 2017 & $\begin{array}{l}\text { Comp. } \\
\text { WMLES }\end{array}$ & Str. & 56.1 & 85 & 12 & $1.7 \times 10^{-5}$ \\
\hline Gao et al. [42] & 2017 & $\begin{array}{l}\text { Comp. } \\
\text { DDES }\end{array}$ & $\begin{array}{l}\text { Unstr. } \\
\text { (SD) }\end{array}$ & 0.34 & 10 & - & - \\
\hline Shi et al. [43] & 2018 & $\begin{array}{l}\text { Comp. } \\
\text { ILES }\end{array}$ & $\begin{array}{l}\text { Unstr. } \\
\text { (FR/CPR) }\end{array}$ & $\begin{array}{l}1.61 \\
5.44\end{array}$ & 68 & 19 & $6.38 \times 10^{-5}$ \\
\hline Ishida [44] & 2019 & $\begin{array}{l}\text { Boltz. } \\
\text { LBM }\end{array}$ & Str. \& Cart. & $\begin{array}{c}6.7 \\
54 \\
430\end{array}$ & - & - & - \\
\hline Housman et al. [45] & 2019 & $\begin{array}{l}\text { Comp. } \\
\text { ZDES }\end{array}$ & $\begin{array}{c}\text { Str. } \\
\text { (LAVA) }\end{array}$ & 36.7 & $\begin{array}{c}256 \\
128 \\
64\end{array}$ & 12.76 & - \\
\hline Sakai et al.[46] & 2019 & $\begin{array}{l}\text { Comp. } \\
\text { DDES }\end{array}$ & Unstr. & 55.7 & 128 & 11.2 & $1.87 \times 10^{-5}$ \\
\hline Ueno \& Ochi [47] & 2019 & $\begin{array}{l}\text { Comp. } \\
\text { SA-DDES }\end{array}$ & Unstr. & $\begin{array}{c}61 \\
242\end{array}$ & - & 10.4 & $7.5 \times 10^{-5}$ \\
\hline Kojima et al. [48] & 2020 & $\begin{array}{c}\text { Comp. } \\
\text { Embedded LES }\end{array}$ & $\begin{array}{c}\text { Unstr. } \\
\text { (FaSTAR) }\end{array}$ & 80 & - & - & $1.43 \times 10^{-5}$ \\
\hline Present & - & $\begin{array}{l}\text { Comp. } \\
\text { DDES }\end{array}$ & Str. & 27 & 44 & 2.3 & $2 . \times 10^{-5}$ \\
\hline
\end{tabular}

\section{B. Computational setup}

The current multiblock structured grid comes from the JAXA website [49]. The computational domain extends 90 chords away from the airfoil. The zoomed 2D cross-section view is shown by Fig. 4. The maximum $\triangle y+$ far from the wall is estimated to be 1.5. To capture the instability shear layer emitting from the slat leading-edge as well as its impingement onto the lower side of slat, the grid resolution in the slat cove is fine enough, shown by Fig. 4(b). And so does the main cove, main trailing-edge and the suction side of the flap, which is shown by Fig. 4(c). The 3D 
grid is generated by extruding the $2 \mathrm{D}$ grid in the spanwise direction for a constant length: $0.0508 \mathrm{~m}$ (corresponding to $0.74 C s$ ), which is the minimum spanwise length determined by the correlation of two-point pressure fluctuations [15]. 44 cells are distributed uniformly along the spanwise direction and the periodic boundary condition is applied. Finally, the 3D grid contains almost 27 million cells in total. In another similar high-lift configuration, the estimated proper spanwise length is $C s[50]$, a little longer than the present $0.74 C s$.

An appropriate choice for time step is also necessary so that a wide range of flow scales can be captured, including the dynamic turbulence structures near the wall, shear layer developments from the slat trailing-edge etc. In this paper, the nondimensionally physical time step is $\Delta t a_{\infty} / 1=0.00005$ (corresponding to $\Delta t U_{\infty} / C=2 . \times 10^{-5}$ and $\Delta t=1.5 \times 10^{-7} \mathrm{~s}$ ). Our calculation shows that there are about 400 time-intervals per vortex shedding of the slat trailing-edge, which indicates the time resolution is high enough in resolving the fine scales. The DDES simulation continues from a RANS flowfield to reduce the time cost in transient procedure. The transient computation lasts for $T U_{\infty} / C=0.2$, computation for the statistical quantities is implemented for $T U_{\infty} / C=2.3$, which is already enough to yield a smooth spectral even though it is shorter than those available in publications. Of course, a longer sampling time will yield a finer identification of the peak tones.

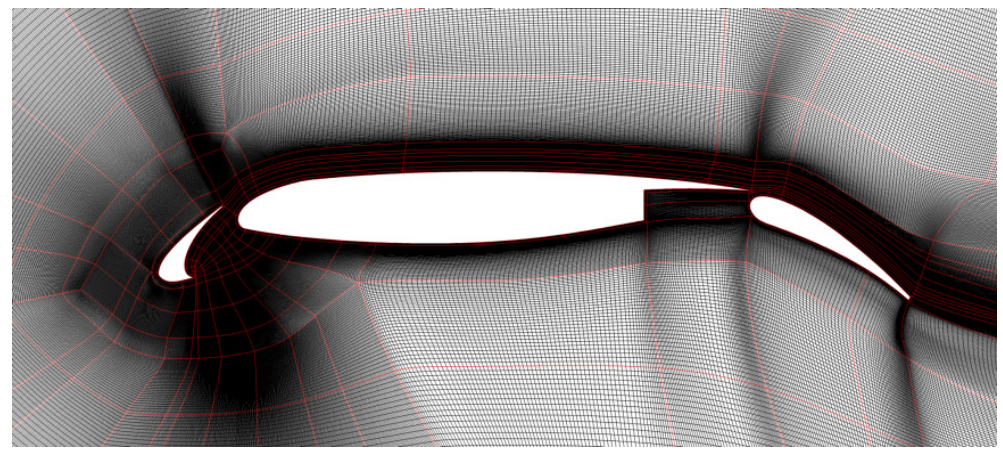

(a) Global view

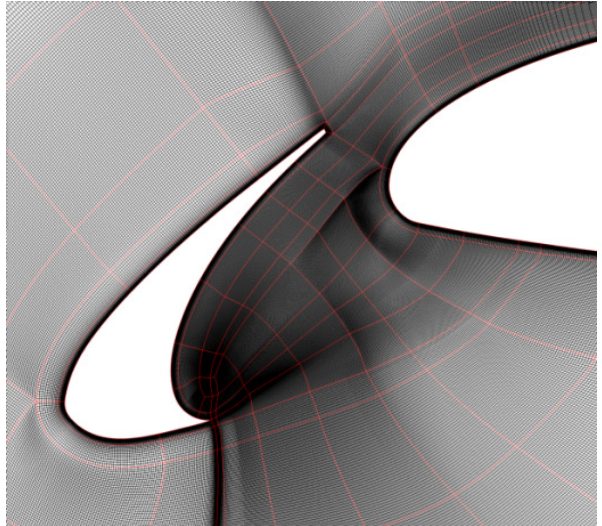

(b) Slat

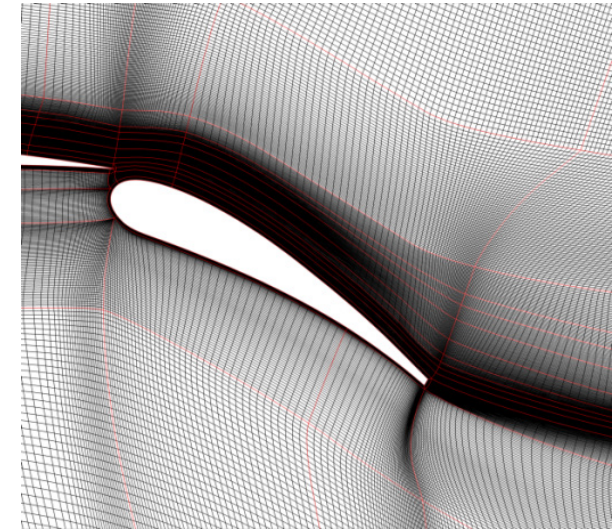

(c) Flap

Fig. 4 Computational grid.

\section{Time averaged pressure coefficients}

The time averaged pressure contour is shown in Fig. 5, where the typical flow structures are marked. The slat and main coves exhibit shallow cavity properties and large recirculation bubbles are formed. The slat leading-edge, slat trailing-edge and main trailing-edge promote the development of shear layers. A flow separation over the backward of flap is clearly observed. And the minimum pressure coefficient exists at the leading suction side of the 
main component. This is because, through the gap between slat and main components, the turbulence vortices suffer from strong stretching and accelerating before interacting with the slat vortex shedding wake. Fig. 6 compares the streamlines surrounding the slat cove with the experiment [18].

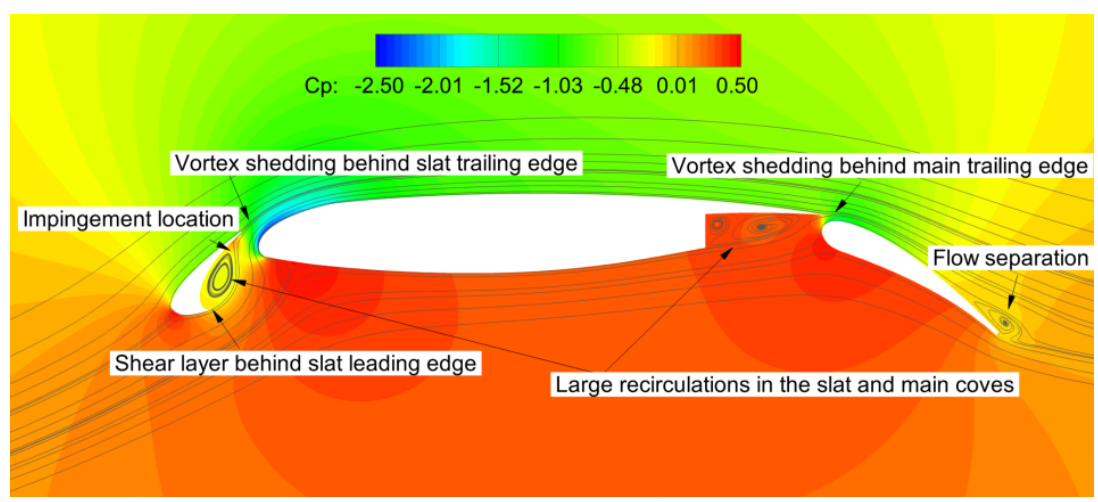

Fig. 5 Pressure coefficient contour.

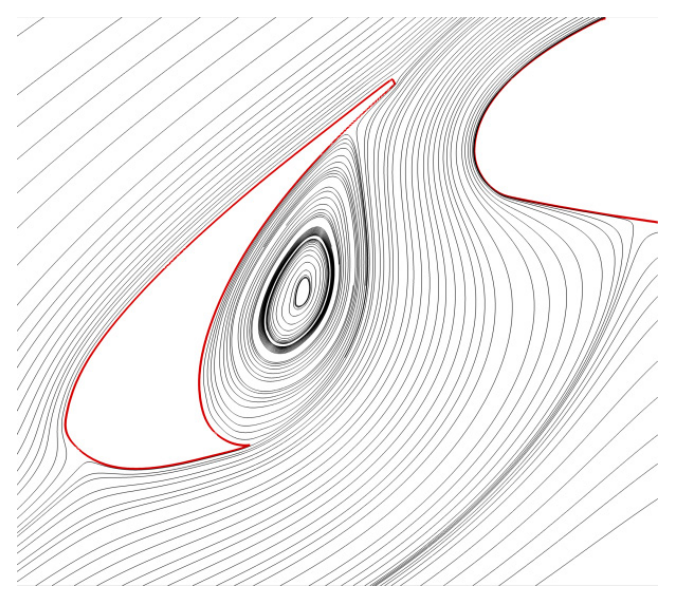

(a) Numerical result

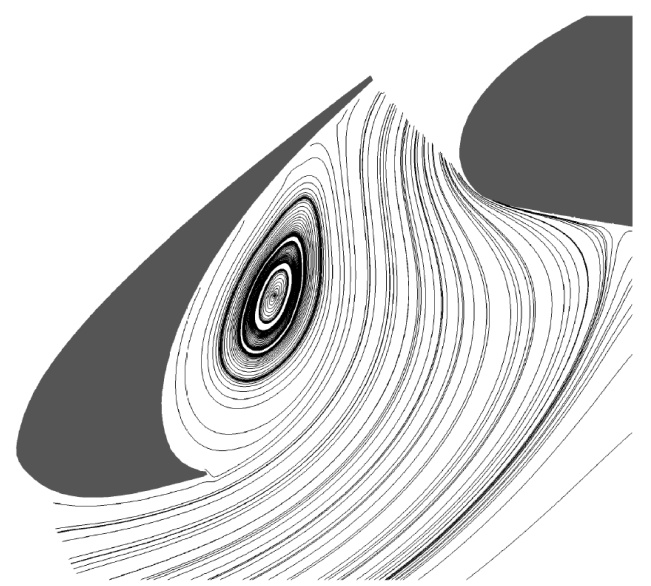

(b) PIV experimental data [18]

Fig. 6 Averaged streamlines around slat.

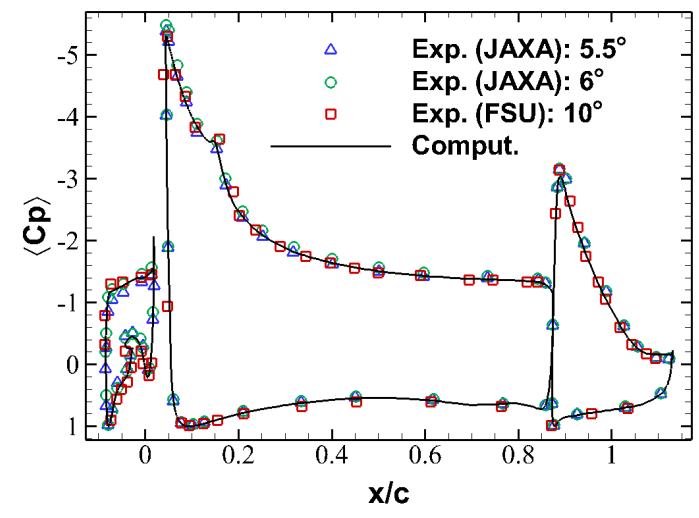

(a) Cp for three elements

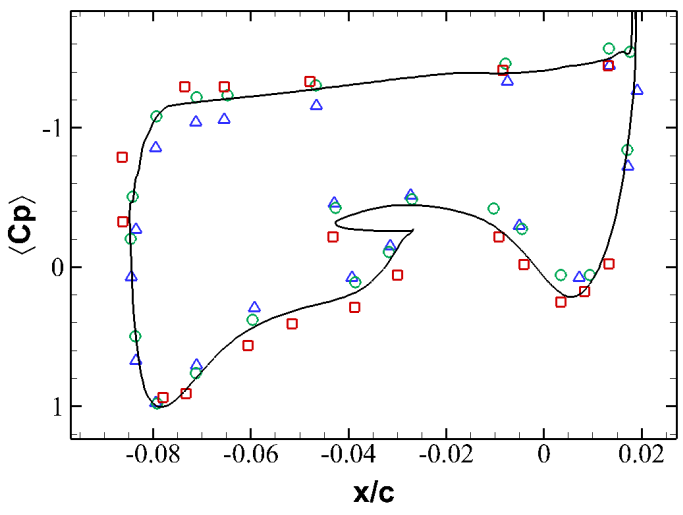

(b) Cp for the slat

Fig. 7 Averaged pressure coefficients on the surface of 30P30N. The JAXA data in hard wind tunnel for 5.5 and $6^{\circ}[16]$, and FSU data in Kevlar wind tunnel for $10^{\circ}[19]$. 
The time averaged pressure coefficients on the surface of the three elements agree reasonably well with the experimental data in Fig. 7. According to Pascioni and Cattafesta [19], $\alpha=10^{\circ}$ from Kevlar wind tunnel in FSU is assumed equivalent to $\alpha=5.5^{\circ}$ from hard wind tunnel in JAXA. In addition, the JAXA data with $\alpha=6^{\circ}$ is also included in Fig. 7 because it is closest to the calculation result.

\section{Instantaneous flowfield visulization}

The dynamic instantaneous flowfield is shown by the isosurfaces of the scaled Q-criterion colored by local Mach number. Fig. 8 shows the whole 30P30N configuration. Around the slat in Fig. 9, the large recirculation bubble in slat cove, the 2D instability shear layer emitting from the cusp of the leading-edge, the gradually formed 3D vortices structures along the shear layer trajectory and the vortex shedding from the trailing-edge, are all clearly observed. The large recirculation bubble will be demonstrated to associated with the low to moderate narrow-band peak tones, whist the shear layers from the leading cusp and the trailing-edge correspond to high-frequency tones, which will be shown later in the wavenumber domain by Fig. 19. Fig. 10 plots the vortices structures on the upper side of flap where the turbulent boundary layer and the wake flow of main component are convected downstream. A separation region is also visible at the rear of flap.

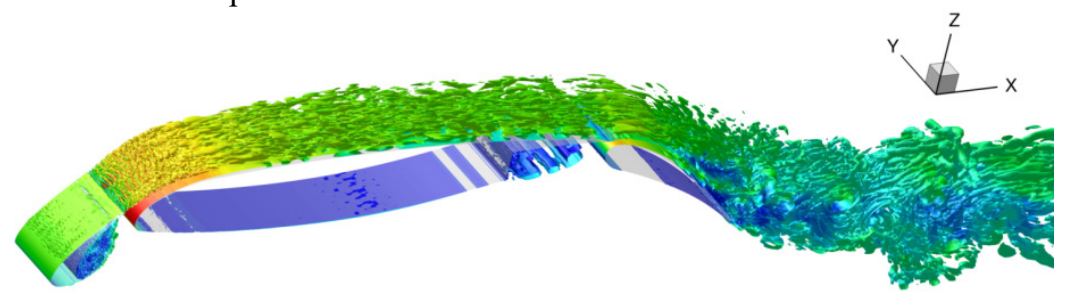

Fig. 8 Isosurface of Q-criterion colored by the Mach number around 30P30N.
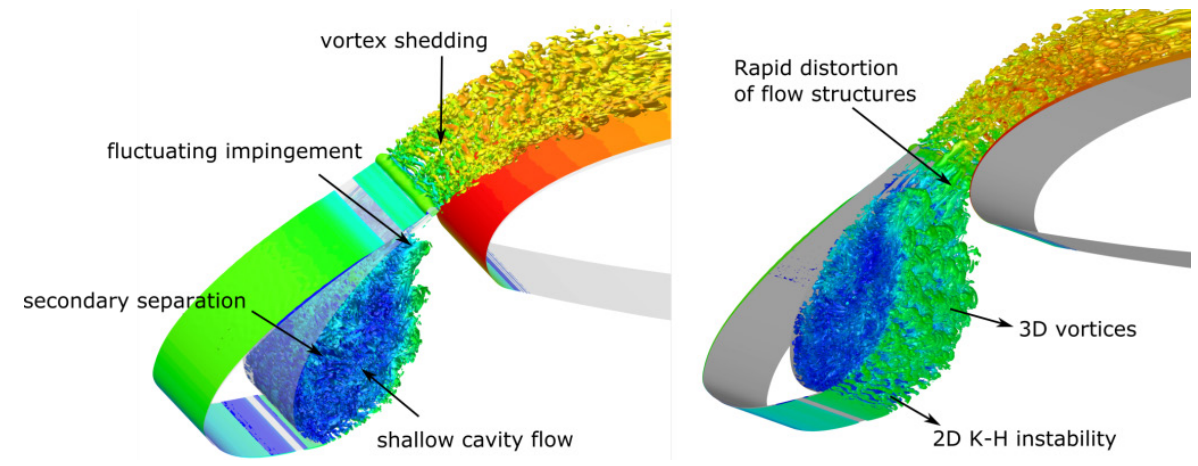

Fig. 9 Isosurface of Q-criterion colored by the Mach number around the slat.

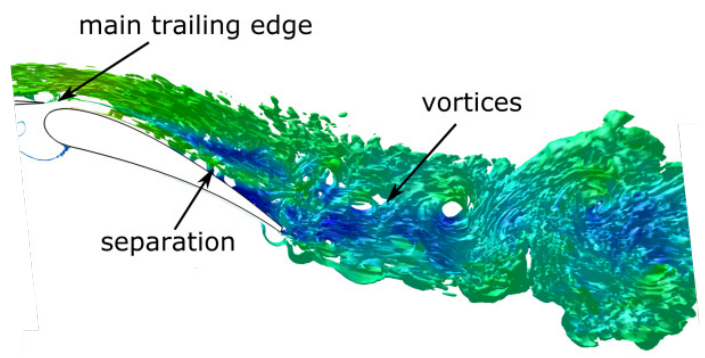

Fig. 10 Isosurface of Q-criterion colored by the Mach number around the flap. 


\section{E. Flowfield contours}

The instantaneous spanwise vorticity contour around the slat is compared with the PIV experimental data [18] in Fig. 11. Strong unsteady fluctuations are observed on the shear layer trajectory, which emits from the cusp of the leading-edge firstly, and then they stretch and merge into 3D vortices before finally impinging onto the lowersurface of the slat. Capturing the dynamic flow structures around the impingement region is really challenging because this area not only involves strong interaction of shear layer with the boundary layer but also induces the flow-acoustic feedback loop (narrow-band peaks in Fig. 19 and Fig. 23). Particularly, a portion of the unsteady flows evolves downstream and gets across the gap between slat and main components before finally merging with the slat trailing-edge flows. Another portion of unsteady flow is trapped in the slat cove and interacts with the shear layer at leading cusp to create a recirculation bubble.

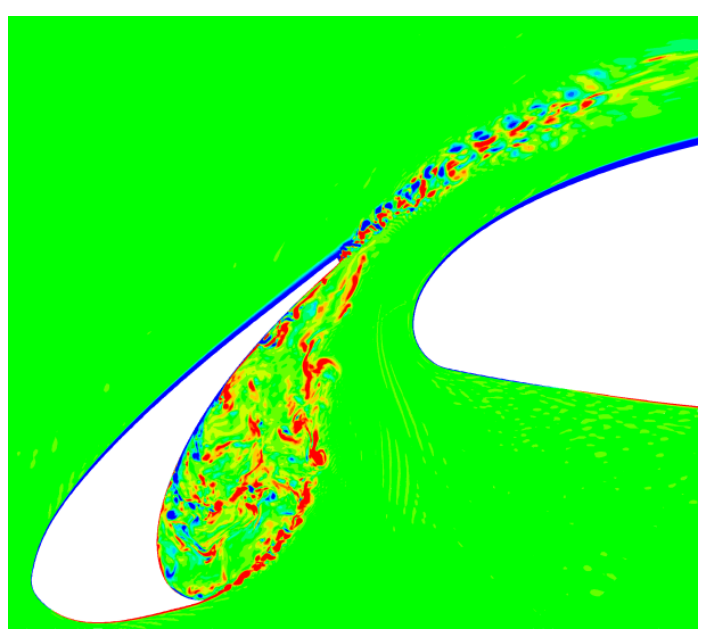

(a) Numerical result

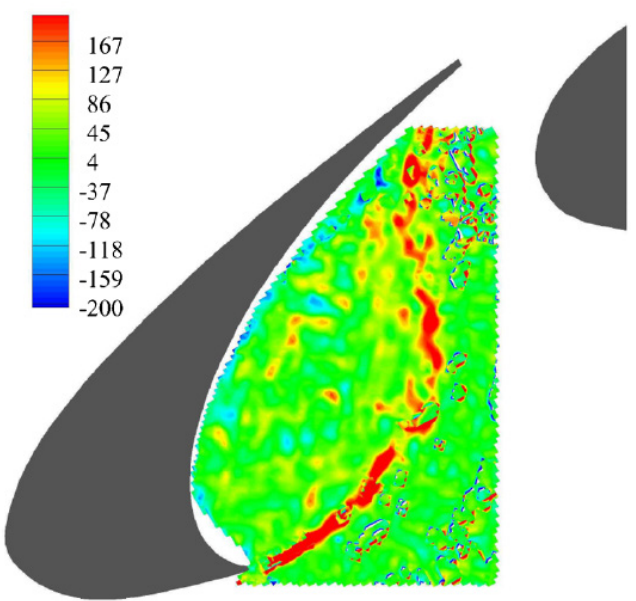

(b) PIV experimental data [18]

Fig. 11 Instantaneous spanwise vorticity contour around slat. The legend is shown in the figure (b).

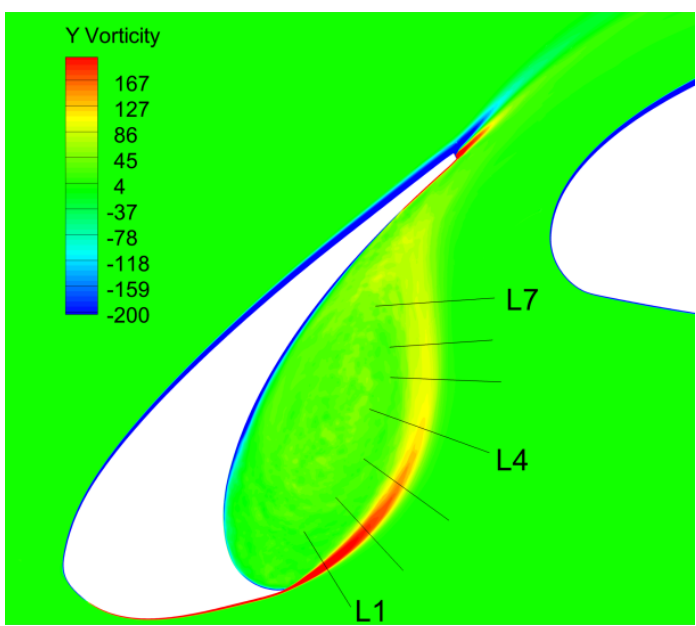

(a) Numerical result

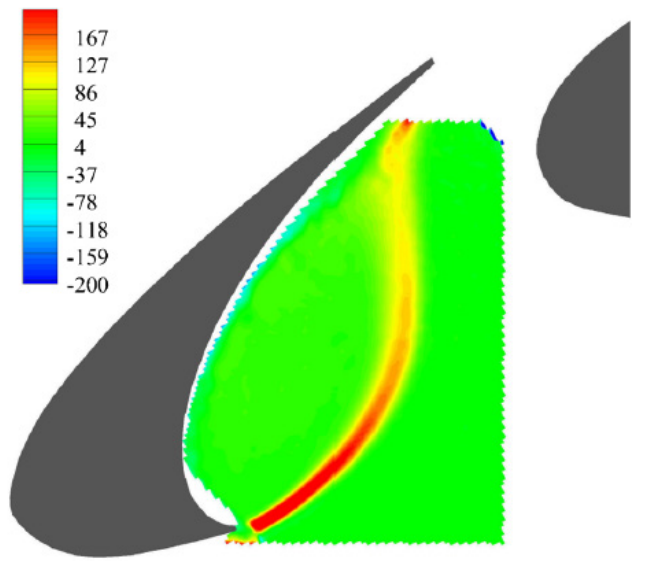

(b) PIV experimental data [18]

Fig. 12 Time averaged spanwise vorticity contour around slat. The legend is shown in the figure (a).

To quantitatively measure the unsteadiness along the shear layer, the profiles along seven lines are compared. The first comparison is the averaged spanwise vorticity: $\Omega C / U_{\infty}$. The contours are given in Fig. 12 where the seven 
lines along the shear layer trajectory are depicted in Fig. 12(a). Fig. 13 indicates the calculated results are in good agreement with the measured results. The relative length is normalized by the length of the line itself. " 0 " represents the left starting point and " 1 " stands for the right ending point.
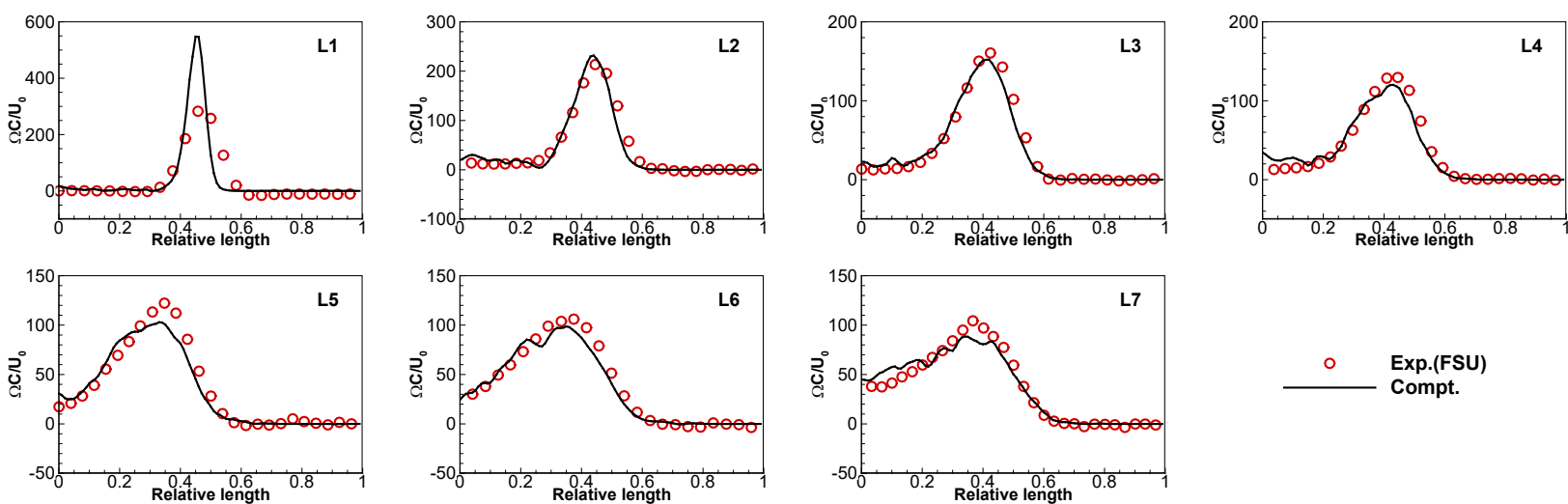

Fig. 13 Spanwise vorticity along the shear layer trajectory at different lines.

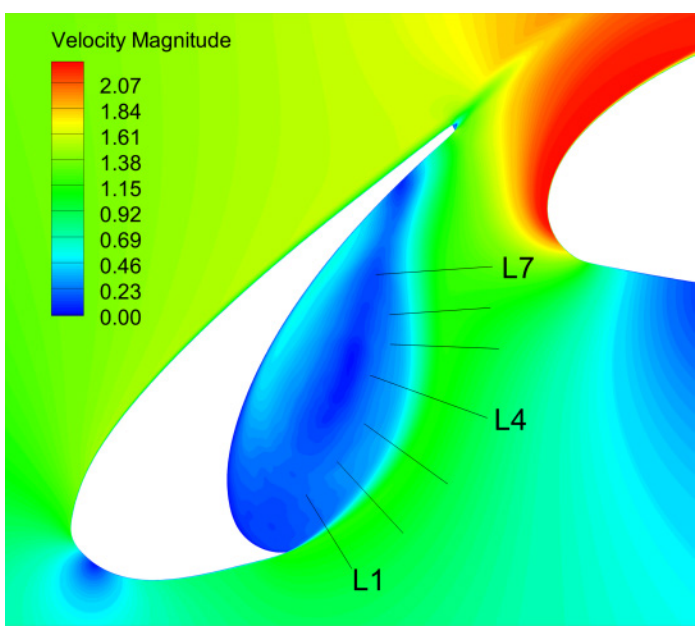

(a) Numerical result

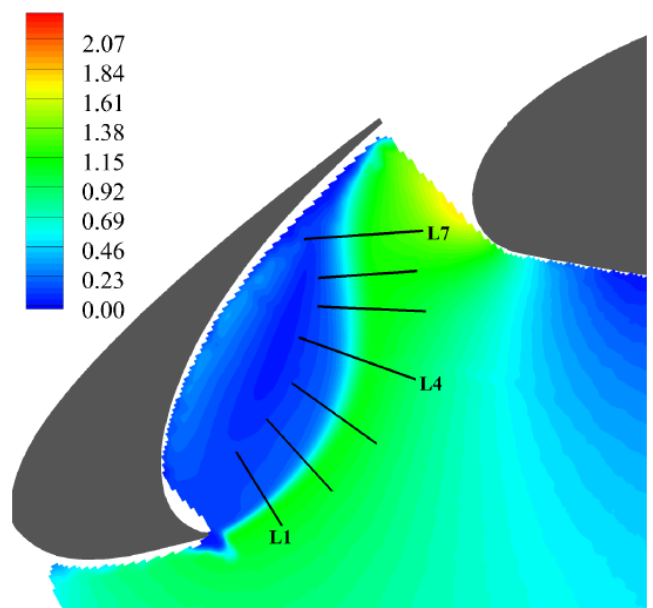

(b) PIV experimental data [18]

Fig. 14 Time averaged velocity magnitude contour around slat. The legend is shown in the figure (a).
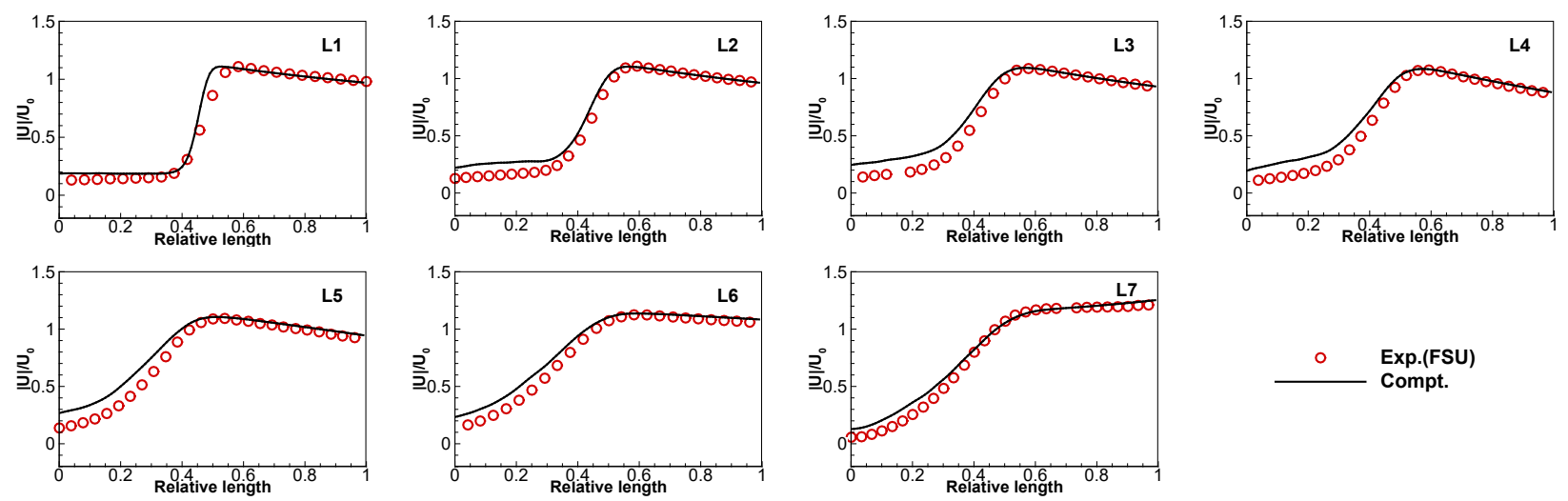

Fig. 15 Velocity magnitude along the shear layer trajectory at different lines. 
The velocity magnitude contours $\left(|U| / U_{\infty}\right)$ are compared in Fig. 14 and the corresponding profiles on seven lines are compared in Fig. 15, where good qualitative and quantitative agreement is obtained.

The turbulence kinetic energy (TKE), $0.5(\langle u u\rangle+\langle v v\rangle+\langle w w\rangle) / U_{\infty}^{2}$, is plotted in Fig. 16 and quantitative comparison along seven cuts with experimental data is shown in Fig. 17. The highest intensities for TKE occur at the reattachment region and the slat trailing-edge region. And a weaker maximum for TKE appears at the slat shear layer, which is due to the laminar-turbulence transition process. TKE can be regarded as a metric for the hydrodynamic intensities and also a useful measurement about the accuracy for aeroacoustic prediction [15]. It is also noted that TKE outside the slat cove is in higher intensity for experiment than calculations. Zhang et al. [41] indicates that based on their communications with Pascioni et al. [18][19], "the unreasonably high level of TKE in the experimental data is likely caused by poor PIV resolution outside the cove vortex because of a particle shortage in that region". Choudhari and Lockard [15] have also pointed out that the low spatial resolution of PIV processing causes the disparity of the initial shear layer thickness.

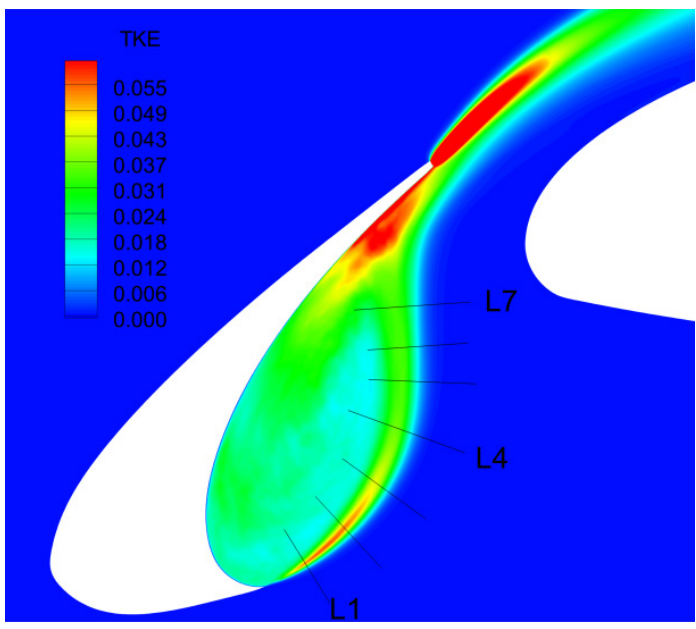

(a) Numerical result
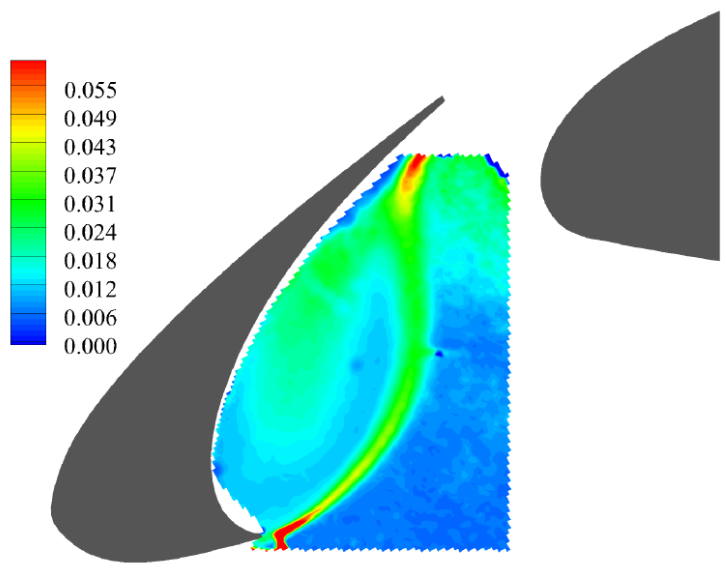

(b) PIV experimental data [18]

Fig. 16 Time averaged turbulence kinetic energy (TKE) around slat. The legend is shown in the figure (a).
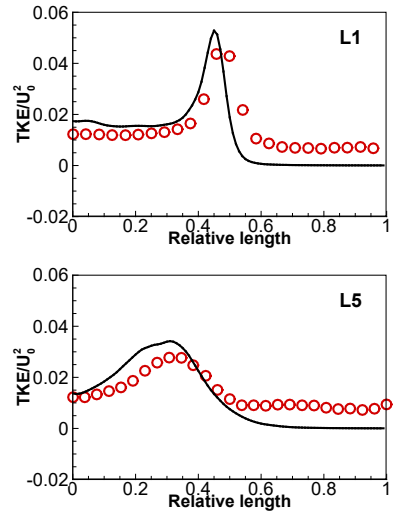
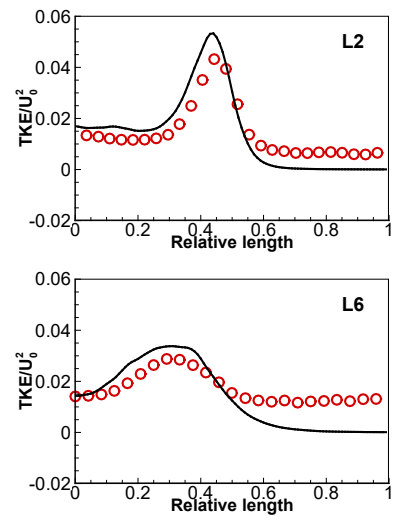
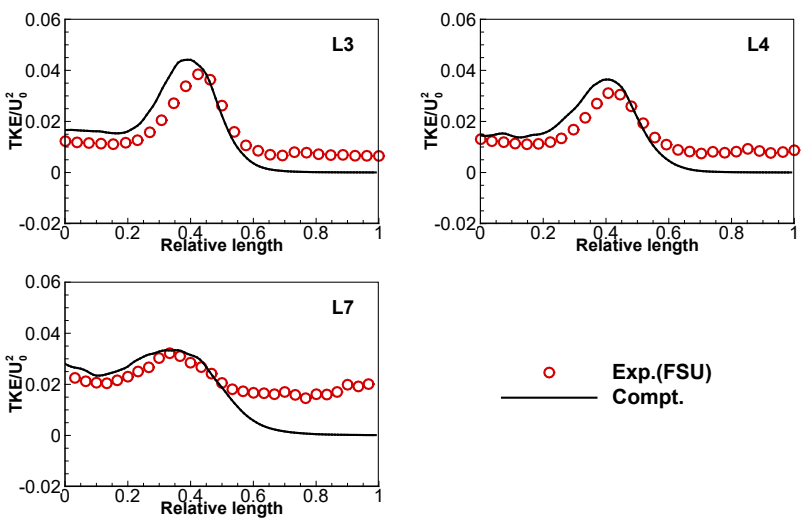

Fig. 17 Time averaged TKE along the shear layer trajectory at different lines.

The studies regarding the flowfield around flap and main is very limited among available literatures. Fig. 18 shows both the instantaneous vorticity field and statistical vorticity field. We can see obviously the unsteady flows due to the trailing-edge vortex shedding from the main component and the flap component. Besides, a massive 
separation occurs on the suction side of the flap, which is inevitable for the deflected flap to meet the high lift level [51]. Deck et al. adopts a backward step flow to analogy this phenomenon [10].

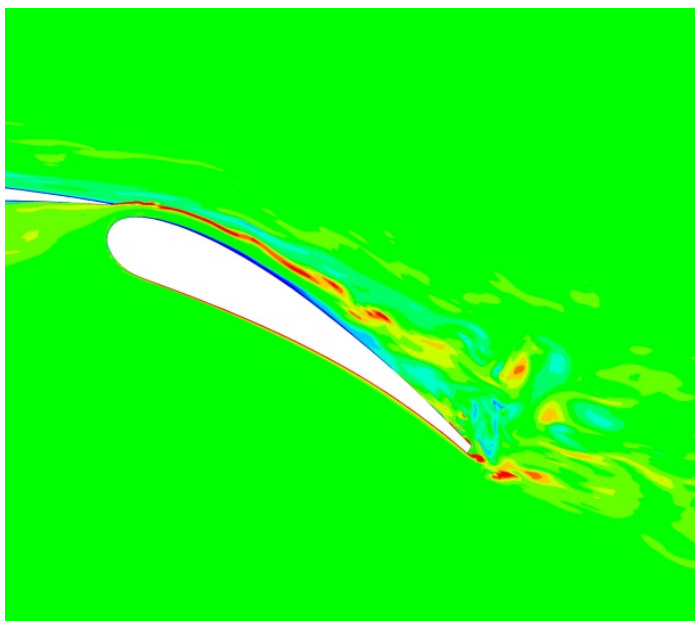

(a) Instantaneous

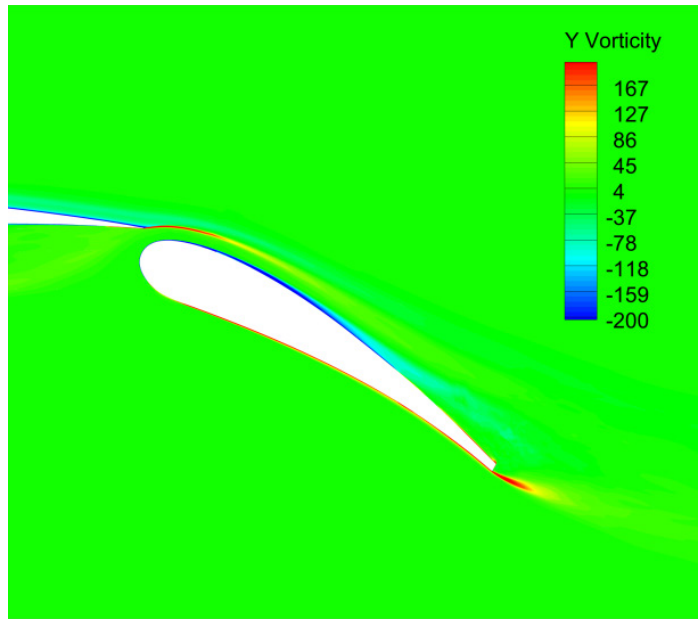

(b) Time averaged

Fig. 18 Spanwise vorticity contour around flap. The legend is shown in the figure (b).

\section{F. PSD of pressure fluctuations and velocity fluctuations}

The power spectral density (PSD) of the dynamic surface pressure fluctuations at five transducers on the slat are shown in Fig. 19 where the experimental data from JAXA [16][17] and FSU [18][19][20] are both used for reference and good agreement is achieved. For $\mathrm{P} 2$ and $\mathrm{P} 6$, the broadband components are accompanied by several narrow-band peak tones (NBPs) in the low frequency region as well as a very high frequency tone at about $21 \mathrm{kHz}$, which is the signature of vortex shedding from slat trailing edge. The NBPs are probably due to fluid-acoustic feedback loop inside the slat, and the high frequency tone corresponds to the trailing-edge vortex shedding process. Besides, P4 and P5 both exhibit high fluctuation levels because they locate at the impingement region.

Fig. 20 compares the computed PSD with the measured PSD at, M1 and F1, two sensors on the main and flap component, respectively, where only the experiment data from JAXA [16][17] are available.

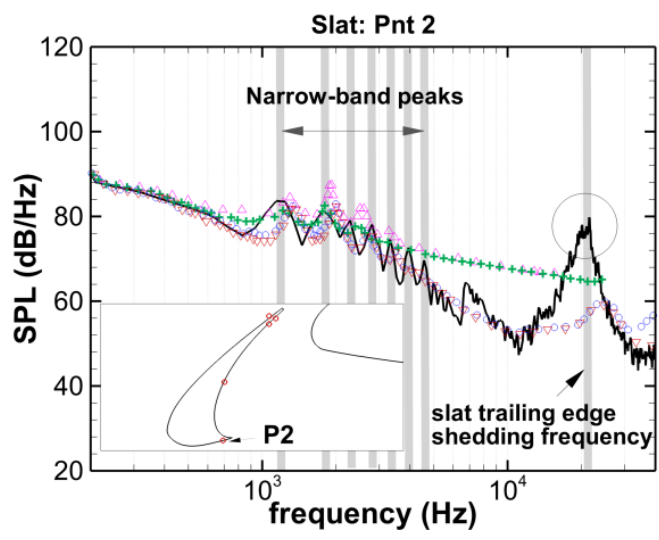

(a) Captions

(b) P2 on slat 


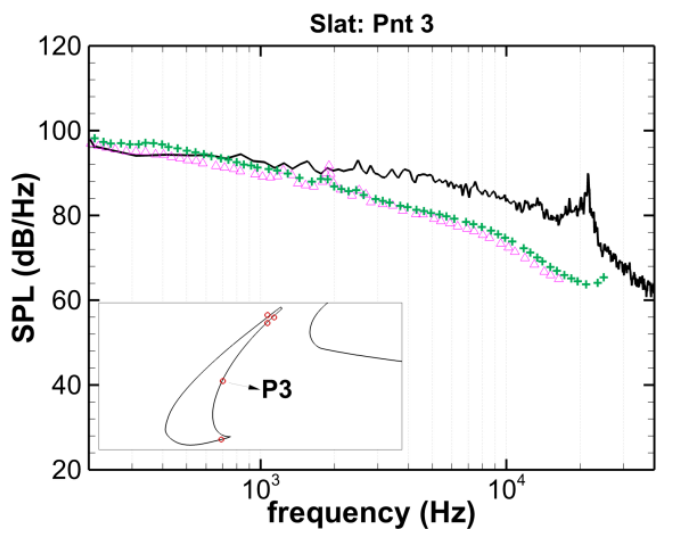

(c) P3 on slat

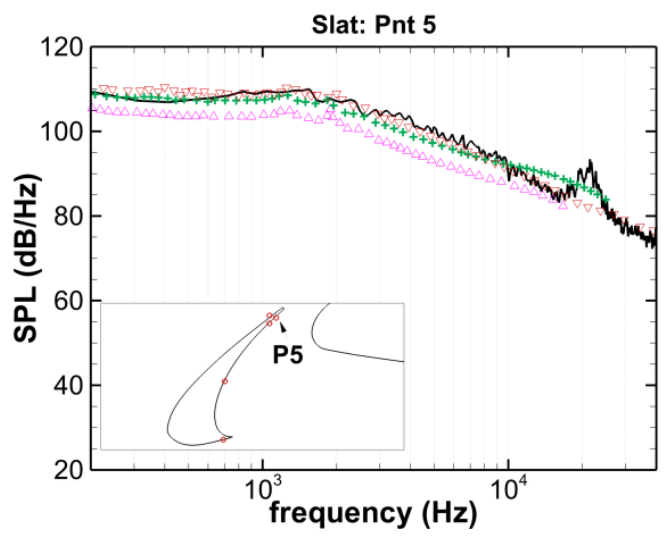

(e) P5 on slat

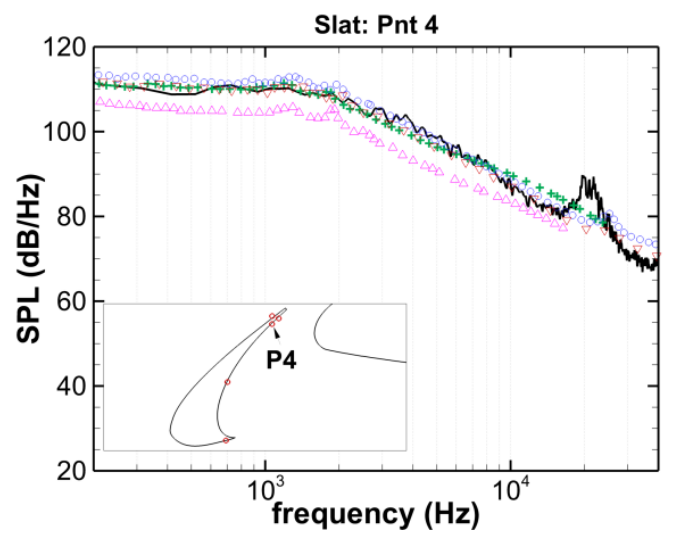

(d) P4 on slat

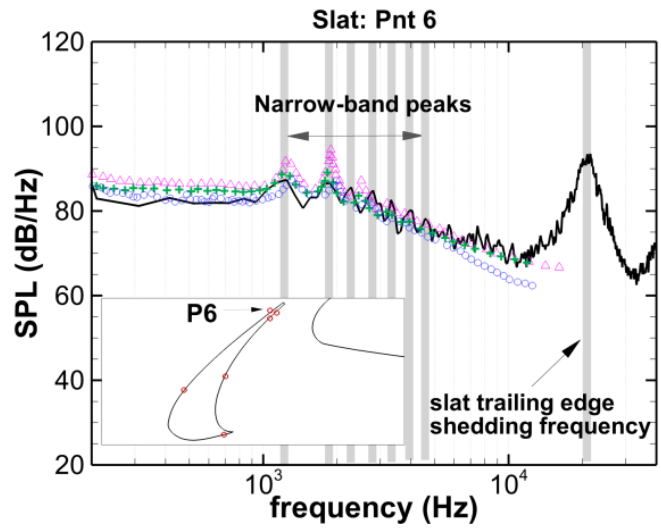

(f) P6 on slat

Fig. 19 PSD of surface pressure fluctuations on the slat. Captions are shown in Fig. 19 (a).

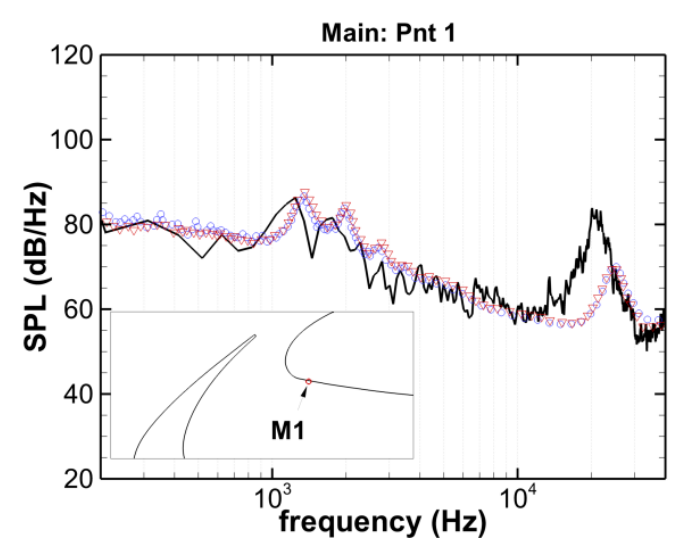

(a) M1 on main

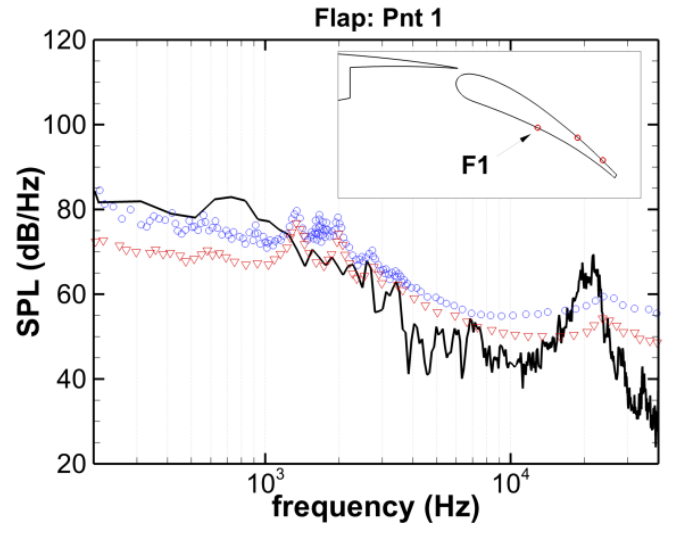

(b) F1 on flap

Fig. 20 PSD of surface pressure fluctuations on the main and flap. Captions are shown in Fig. 19 (a).

Furthermore, a snapshot of spanwise pressure gradient superimposed over the spanwise vorticity contours is shown by Fig. 21 where the acoustic radiation is evidently predicted. The slat appears to be a dominant contributor to the noise emission. The flap trailing edge also yields acoustics whose wavelength almost equivalent to that originating from the slat trailing edge. The main trailing edge gives waves with shorter wavelength. 


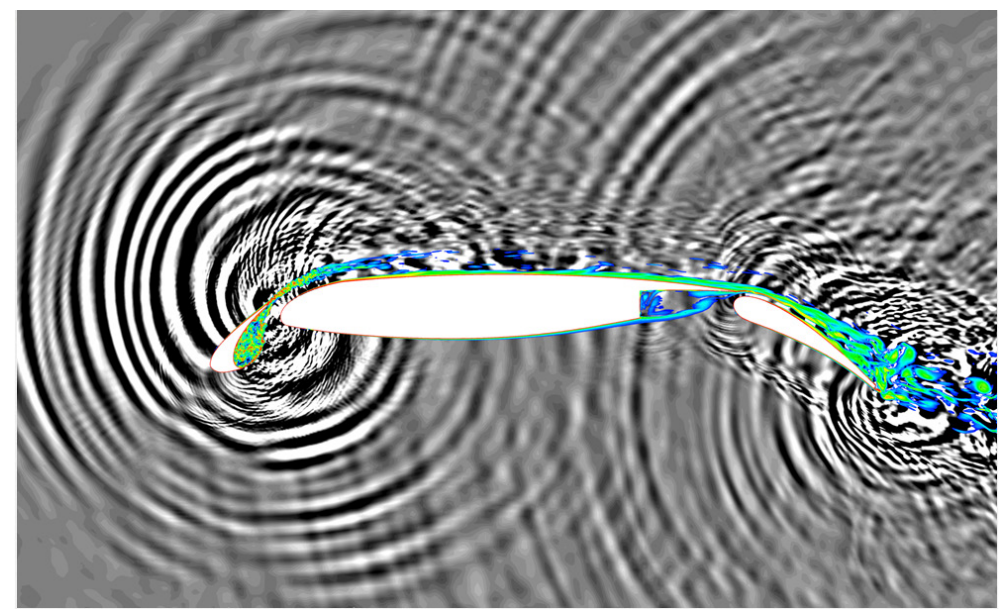

Fig. 21 Snapshot of pressure gradient contour superimposed over the spanwise vorticity contour.

For further analysis, the pressure transducers, SJ1 to SJ6 surrounding the slat is shown by Fig. 22 (a). Fig. 23 compares the PSD of surface pressure fluctuations at SJ1 to SJ6. It is clearly shown that, SJ1, SJ2 and SJ6 exhibit apparent narrow-band peaks at several discrete frequencies: $1243 \mathrm{~Hz}, 1855 \mathrm{~Hz}, 2266 \mathrm{~Hz}, 2792 \mathrm{~Hz}, 3327 \mathrm{~Hz}, 3931 \mathrm{~Hz}$ and $4531 \mathrm{~Hz}$. The interval between two frequencies approximates $600 \mathrm{~Hz}$. This is attributed to the resonant feedback mechanism and can be interpreted by the Rossiter modes in cavity $(1290 \mathrm{~Hz}$ and $1935 \mathrm{~Hz}$ by Terracol et al. [39] ). Though the present work has not carry out this theoretical part, but more models can be found by Terracol et al. [52] and Deck et al. [10]. The feedback acoustics are likely caused by the impingement of the shear layer vortices originating from the leading cusp of slat with the upper side of slat. SJ4 and SJ5 are the closest to the impingement location, so strongest turbulence intensities are evidenced.

In addition, the high frequency tone at about $21 \mathrm{kHz}(25 \mathrm{kHz}$ in the experiment) and its first harmonic $42 \mathrm{kHz}$ corresponds to the regularly slat trailing-edge vortex shedding. This tone is also predicted numerically by Sakai et al. [46] and Ueno et al. [47], yet, not one can get the amplitude for this tone exactly agreeing well with experimental data. We also notice a small peak for SJ1 and SJ2 at around $6.5 \mathrm{kHz}$. An approximate peak is also noticed by Terracol et al. [39] (7kHz), Lockard et al. [38] and Housman et al. [45] (6785Hz). Housman claimed this frequency exactly corresponds to the acoustic wavelength equivalent to the spanwise length $0.0508 \mathrm{~m}$. Lockard removed this spurious tone by modeling a larger span length.

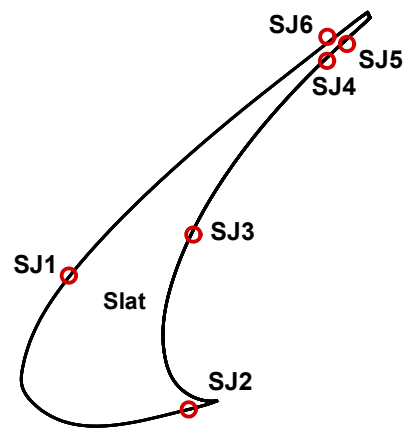

(a) Pressure sensors

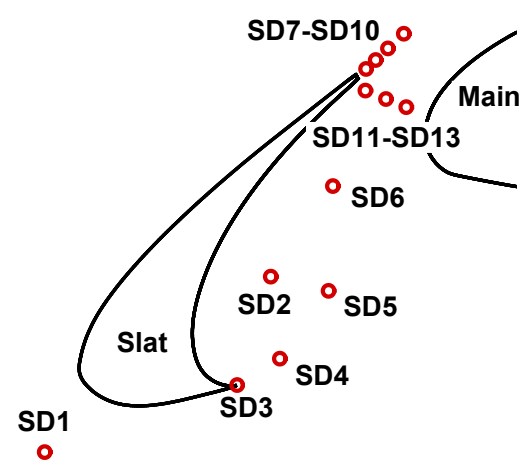

(b) Velocity sensors

Fig. 22 Sensors surrounding the slat element. 


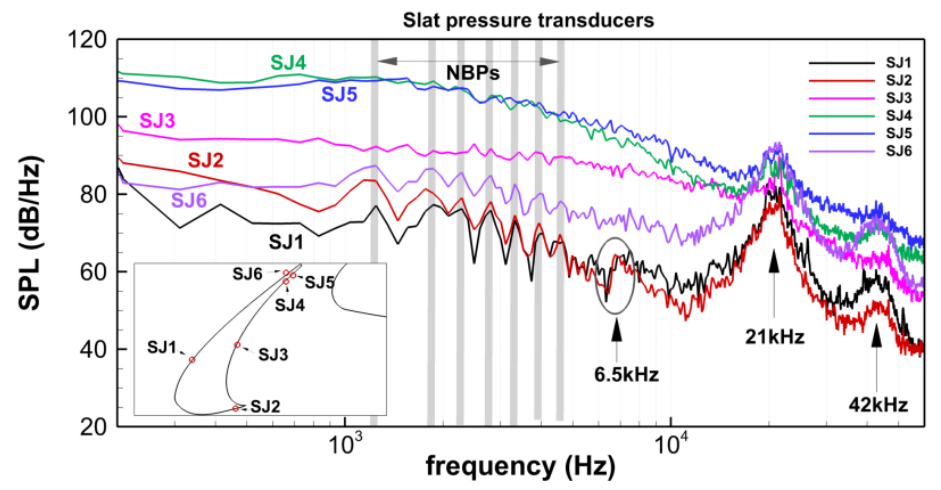

Fig. 23 PSD of surface pressure fluctuations on the slat element.

The fluctuation velocity sensors, SD1 to SD13, are shown by Fig. 22(b). For clarity, we classify these transducers into two categories in terms of their positions. SD1-SD6 are denoted as the first group; SD7-SD13 are denoted as the second group.

Regarding the first group, SD1 lies on the streamline of incoming flow direction, SD2 locates at the center of recirculation bubble and SD3 to SD6 locate on the shear layer trajectory. In Fig. 24, the fluctuation level for SD1 is much lower than that of the other sensors. This is because SD1 locates at the incoming flow streamline where the turbulent level remains small. Besides, SD3 and SD4 yield a visible hump around 21kHz, whereas SD2, SD5 and SD6 yield broadband contents. This hump is linked to the process of the 2D Kelvin-Helmholtz instability development on the shear layer trajectory. By contrast, SD5 and SD6 have been through the transition from 2D laminar to 3D fully-developed turbulence so that the peak is disappeared and a broadband characteristic is predicted. Additionally, SD2, at the recirculation center of the slat cove also exhibits broadband property, but the dynamic intensity level is lower than that of SD5 and SD6.

Regarding the second group (Fig. 25), because SD7 to SD10 are in the near wake of the slat trailing-edge, the three tones at $21 \mathrm{kHz}, 42 \mathrm{kHz}$ and $63 \mathrm{kHz}$, corresponding to the fundamental vortex shedding frequency and the first two harmonics, are apparently observed. SD11 and SD12 behave broadband contents in lower levels.

The acoustic field relating to the slat is shown by Fig. 26.

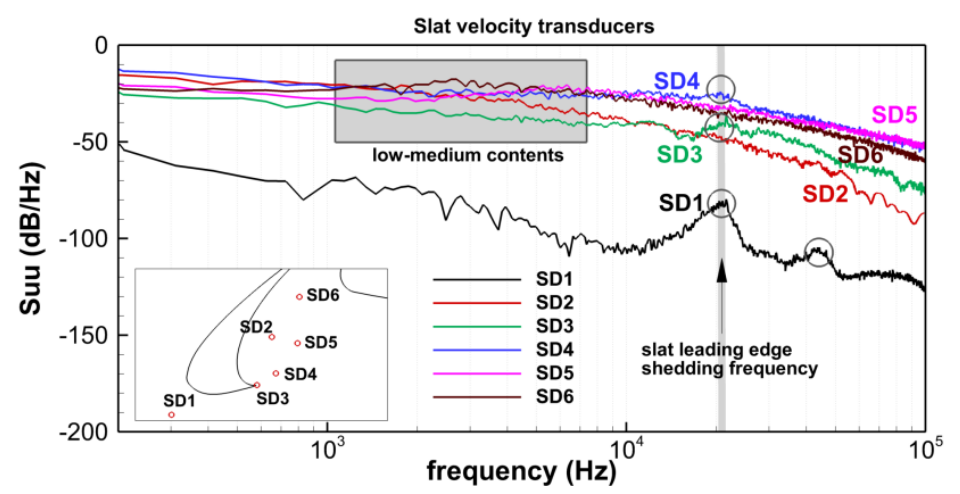

Fig. 24 PSD of streamwise velocity fluctuations around the slat cove region. 


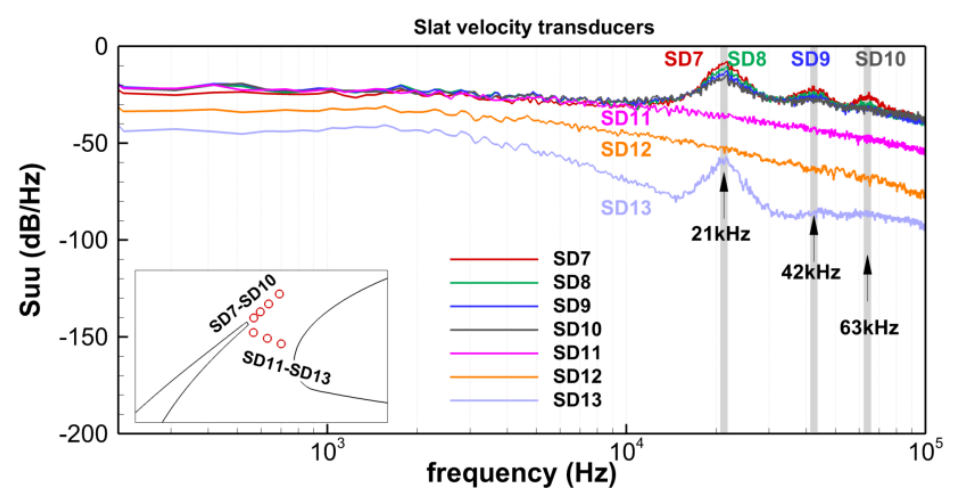

Fig. 25 PSD of streamwise velocity fluctuations around the slat trailing-edge.

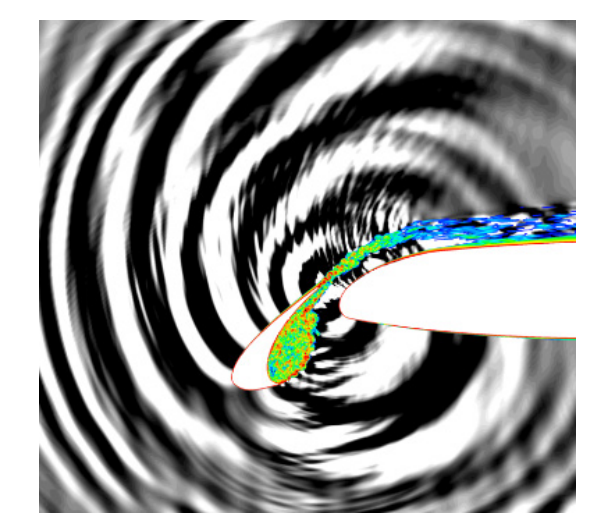

Fig. 26 Pressure gradient contour around the slat element.

The pressure transducers and velocity transducers on the main element are shown in Fig. 27(a) and (b) respectively.

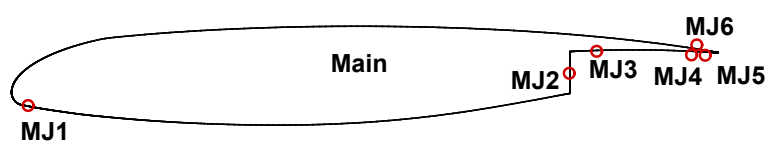

(a) Pressure sensors

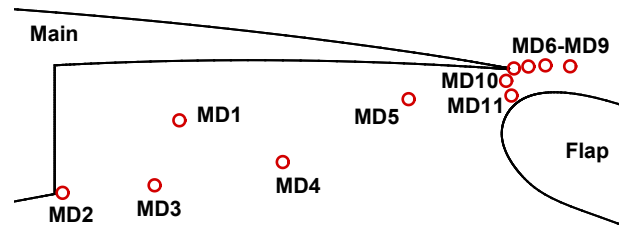

(b) Velocity sensors

Fig. 27 Sensors surrounding the main element.

Fig. 28 draws the PSD of surface pressure fluctuations at sensors on main component shown by Fig. 27(a). Compared with the sensors on slat in Fig. 23, the turbulent levels for sensors on main component are lower in terms of low to medium frequency (larger than $1 \mathrm{kHz}$ and lower than $10 \mathrm{kHz}$ ). In the high frequency range, MJ1 yields a peak at $21 \mathrm{kHz}$ as well as its first harmonic, which owes to the slat trailing-edge vortex shedding. The downstream MJ2 and MJ3 are also affected by the tone at 20kHz. Apart from 20kHz, MJ4, MJ5 and MJ6 also show additional tone at $40 \mathrm{kHz}$, corresponding to the main trailing-edge vortex shedding. This fact indicates MJ4, MJ5 and MJ6 are 
affected by all the slat/main/flap trailing edge shedding frequencies. Additionally, the reason for a frequency jump at $6.5 \mathrm{kHz}$ has already been explained in the interpretation of Fig. 23.

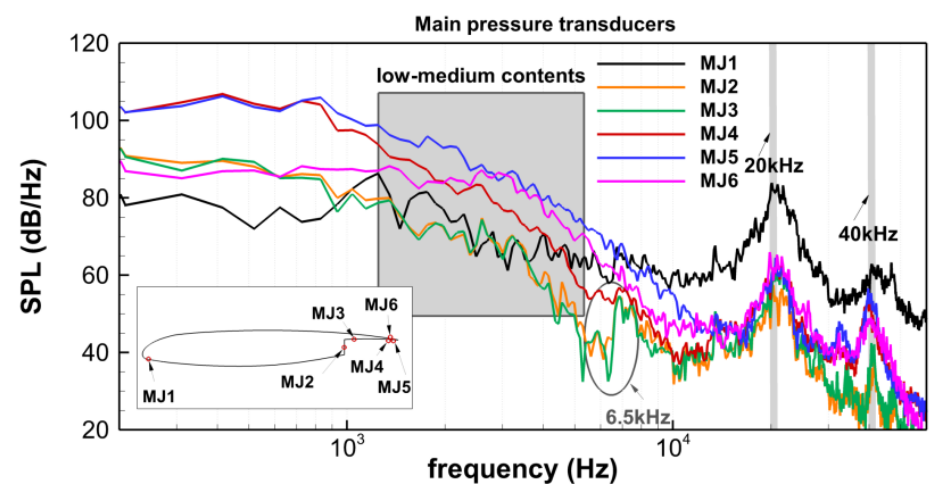

Fig. 28 PSD of surface pressure fluctuations on the main element.

For clarity, we also classify the velocity sensors on main element, MD1 to MD11 shown by Fig. 27 (b), into two categories in terms of their positions. MD1-MD5 are denoted as the first group; MD6-MD11 are denoted as the second group.

Analysis of the first group, MD1 to MD5, is given in Fig. 29. MD1 is at the centroid of the recirculation bubble of the main cove, MD2 to MD5 are on the shear layer emitting from the main cove leading cusp. In terms of the low to medium contents, the fluctuation levels for MD1 and MD2 are evidenced lower than that of MD3 and MD4. Besides, MD5 yields the highest intensity. With regard to high frequency content, a broadband peak at $20 \mathrm{kHz}$ is found for MD1 to MD4, which is due to the combination influence of the upstream slat trailing-edge noise and downstream flap trailing-edge noise. MD5 exhibits differently where a peak at $40 \mathrm{kHz}$ as well as its harmonic peak at $80 \mathrm{kHz}$ is observed. This is easy to be understood because MD5 lies very close to the rear of the main element, so it is obviously affected by the main trailing-edge.

Analysis of the second group, MD6 to MD11, is given in Fig. 30. Since MD6 and MD7 are in the near wake of the main trailing-edge, the tone at $40 \mathrm{kHz}$ induced by shedding wake of main component and its several harmonics (around $80 \mathrm{kHz}, 120 \mathrm{kHz}, 160 \mathrm{kHz}, 200 \mathrm{kHz}$ etc.) are clearly observed. Comparatively, MD8 and MD9, due to their locating further downstream, the peaks disappear and are replaced by broadband parts. Moreover, the evidence that MD10 and MD11 again exhibit the peak tones indicates the gap region between main and flap is largely affected by the main trailing-edge.

The acoustic field relating to the main component is shown by Fig. 31.

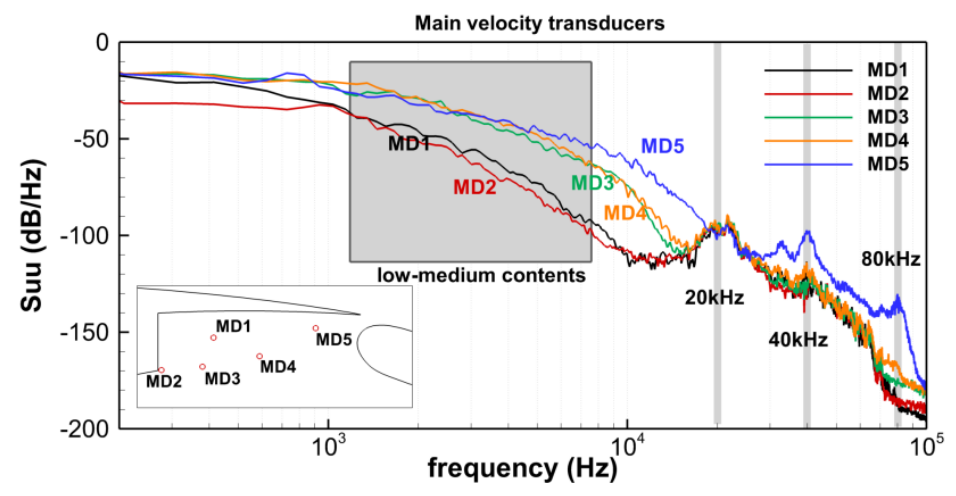

Fig. 29 PSD of streamwise velocity fluctuations around the main cove region. 


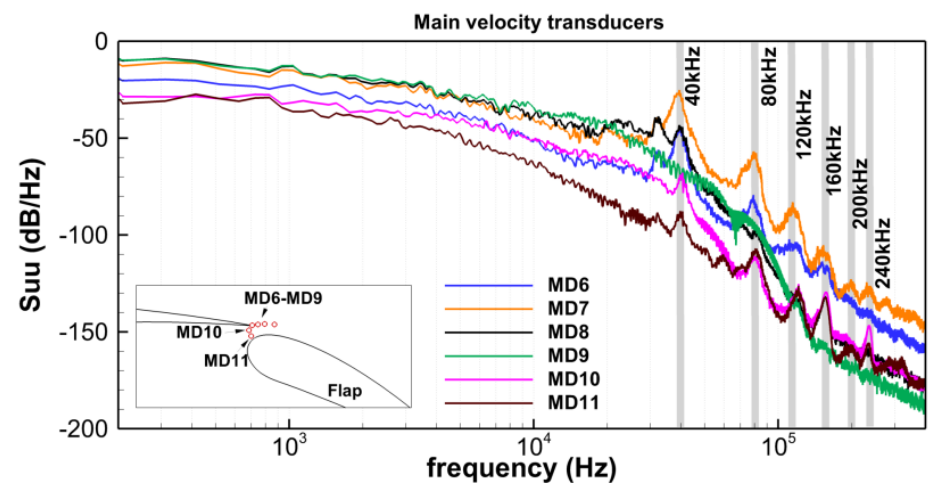

Fig. 30 PSD of streamwise velocity fluctuations around the main trailing-edge.

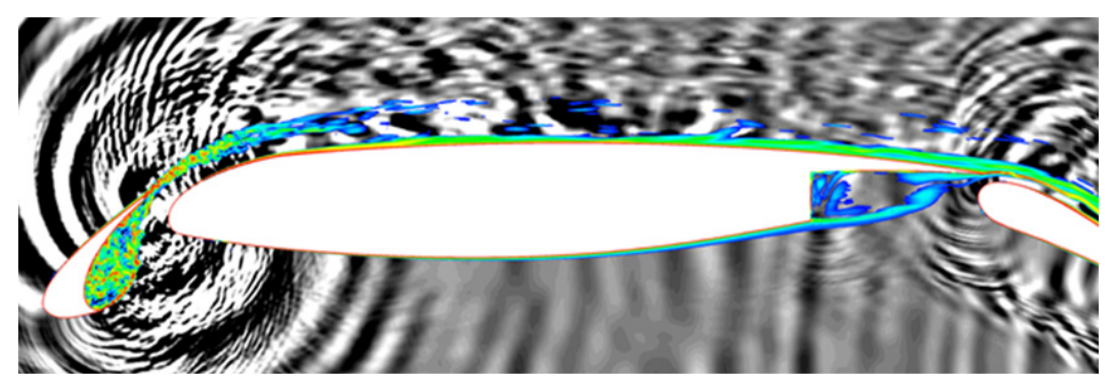

Fig. 31 Pressure gradient contour around the main element.

The pressure transducers (FJ1, FJ2 and FJ3) and velocity transducers (FD1 to FD6) surrounding the flap component are shown in Fig. 32 (a) and (b) respectively.

Fig. 33 draws the PSD of surface pressure fluctuations for sensors FJ1, FJ2 and FJ3. The sensor FJ1 exhibits lower unsteady fluctuation levels than FJ2 and FJ3 in terms of the low and medium range. The broadband hump approximating $8 \mathrm{kHz}$ is characterized by the turbulence wake of flap. And the peak tones at $20 \mathrm{kHz}$ and $40 \mathrm{kHz}$ are induced by the flap trailing-edge vortex shedding.

Fig. 34 demonstrates that all the velocity sensors exhibit a broadband characteristic. And FD1 has lower intensity than the others. Deck et al. [10] pointed out the flap flow is analogy to the backward facing step flow.

The acoustic field relating to the flap component is shown by Fig. 35.

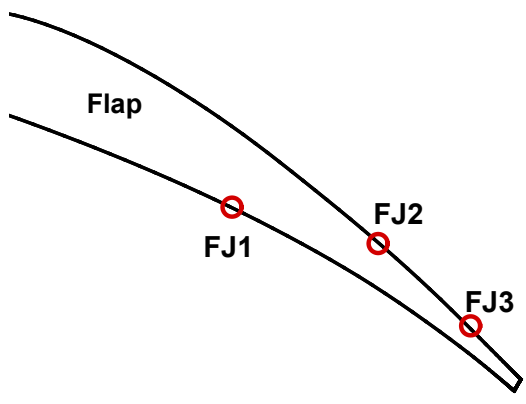

(a) Pressure sensors

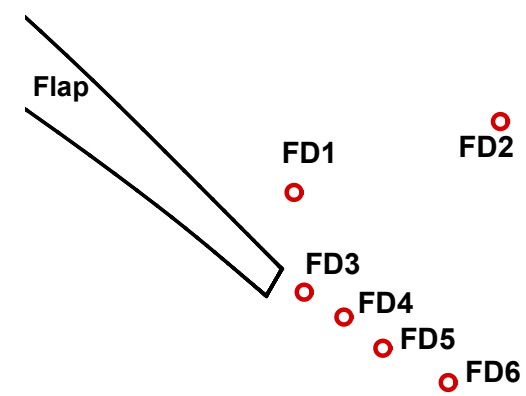

(b) Velocity sensors

Fig. 32 Sensors surrounding the flap element. 


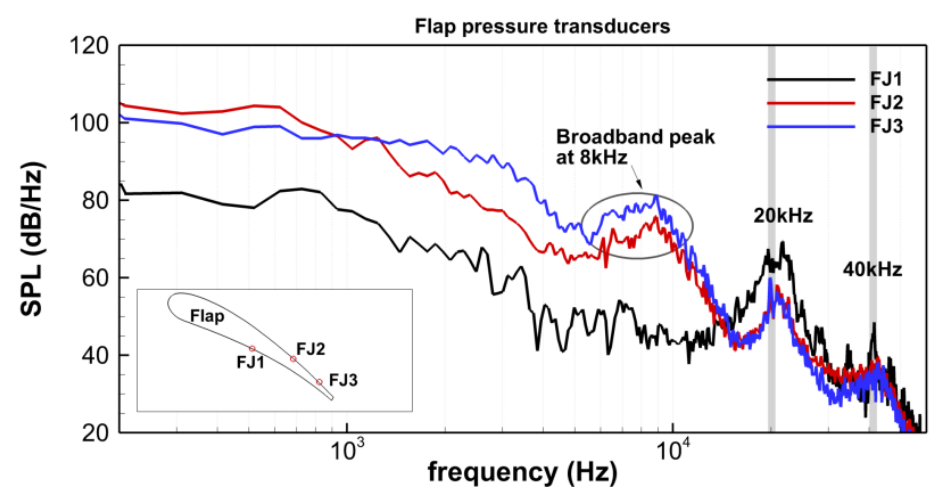

Fig. 33 PSD of surface pressure fluctuations on the flap element.

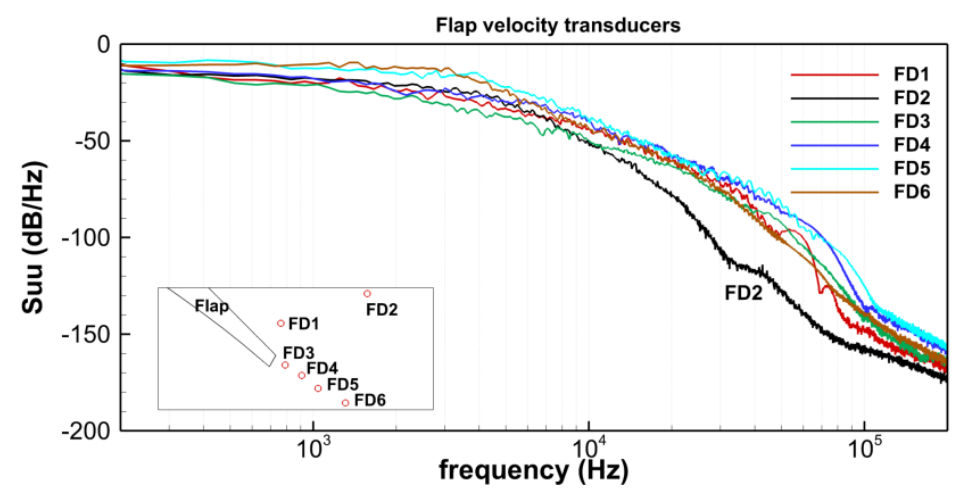

Fig. 34 PSD of streamwise velocity fluctuations around the flap trailing-edge.

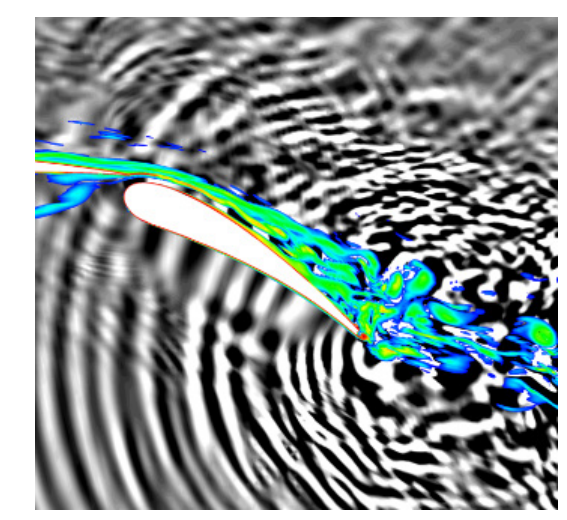

Fig. 35 Pressure gradient contour around the flap element.

\section{Conclusion}

In this paper, an in-house code based on a cell-centered finite difference method with delayed detached-eddy simulation is employed to investigate the aerodynamic and aeroacoustic properties of the modified 30P30N multielement high-lift airfoil. The experimental data from JAXA and FSU are used for quantitative comparisons. The calculated results agree reasonably well with the measured data in terms of the averaged quantities and fluctuating statistics. The physical mechanism relating to the unsteadiness, turbulent structures, narrow-band peaks associated with acoustic feedback loop etc. are all discussed. PSD analysis of additional numerical probes is implemented to in 
depth investigate the types of noise sources. To sum up, the slat cove and main cove both function as shallow cavities. In terms of low-to-moderate frequencies, the slat cove shows noticeable narrow-band peaks whist main cove yields more broadband contents. Besides, the slat trailing-edge, main trailing-edge and flap trailing-edge all yield high frequency tones due to regular vortex shedding, corresponding to $21 \mathrm{kHz}, 40 \mathrm{kHz}$ and $20 \mathrm{kHz}$, respectively. In addition, large massive separation occurs on the suction side of the flap, which results in the disappearance of the tones but yields the broadband contents. The acoustic field also demonstrates the slat component is a major noise contributor.

\section{Acknowledgments}

This research is supported by the project of China (No. B17037) and the National Natural Science Foundation of China (No. 91952203). The authors also acknowledge the National Supercomputer Center in Guangzhou (NSCCGZ) for providing computing time on the Tianhe-2 supercomputer.

\section{Appendix}

\section{A. Power Spectral Density (PSD)}

For a discrete sound signals $p_{n}, 1 \leq n \leq N$, the PSD is given by

$$
S_{p p}(\omega)=2 \frac{N}{f_{s}}\left|\frac{1}{N} \sum_{n=1}^{N} p_{n} \exp (-i \omega n \delta t)\right|^{2} .
$$

The sound power level (SPL) is evaluated by

$$
S P L(\omega)=10 \log _{10}\left(\frac{S_{p p}(\omega)}{P_{r e f}^{2}}\right),
$$

where $P_{\text {ref }}=2 \times 10^{-5} \mathrm{~Pa}$. In this paper, we adopt window function before implementing the Fast Fourier Transform and average the sub-segments of the data to eliminate the spectral disparity.

\section{B. Additional transducers for the pressure and velocity fluctuations}

The coordinate of seven lines, the static pressure sensors on the surfaces and dynamic velocity pressure sensors are given below. The coordinates are normalized by $1 \mathrm{~m}$.

Tab. 3 Coordinate of seven cutting lines in Fig. 12, Fig. 14 and Fig. 16 along the slat shear layer trajectory.

\begin{tabular}{ccc}
\hline \hline & Starting point & Ending point \\
\hline L1 & $(-0.0097843,-0.042645)$ & $(-0.0040602,-0.051872)$ \\
L2 & $(-0.0059370,-0.038544)$ & $(-0.0022806,-0.047464)$ \\
L3 & $(-0.0025856,-0.033866)$ & $(0.0078171,-0.041392)$ \\
L4 & $(-0.0018751,-0.027887)$ & $(0.012723,-0.033202)$ \\
L5 & $(0.0006317,-0.024066)$ & $(0.014144,-0.024608)$ \\
L6 & $(0.0005379,-0.020406)$ & $(0.013099,-0.019539)$ \\
L7 & $(-0.0011512,-0.015458)$ & $(0.013367,-0.014458)$ \\
\hline \hline
\end{tabular}



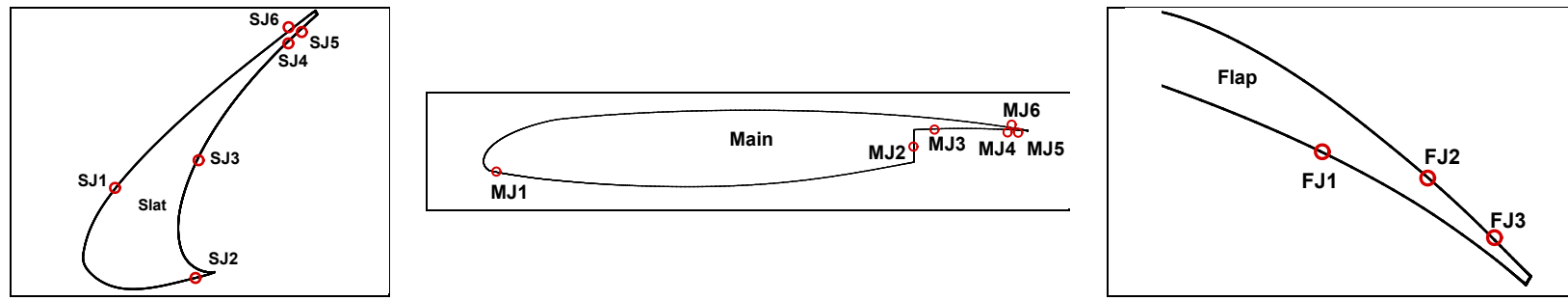

Fig. 36 Static surface pressure probes.

Tab. 4 Coordinate of static surface pressure probes.

\begin{tabular}{lccccc}
\hline \hline & Slat & & Main & Flap \\
\hline SJ1 & -0.032100 & MJ1 & 0.029518 & FJ1 & 0.457959 \\
SJ2 & -0.015900 & MJ2 & 0.320044 & FJ2 & 0.488069 \\
SJ3 & -0.015343 & MJ3 & 0.334597 & FJ3 & 0.506743 \\
SJ4 & 0.002653 & MJ4 & 0.385814 & & \\
SJ5 & 0.005268 & MJ5 & 0.392126 & & \\
SJ6 & 0.002962 & MJ6 & 0.388792 & & \\
\hline \hline
\end{tabular}
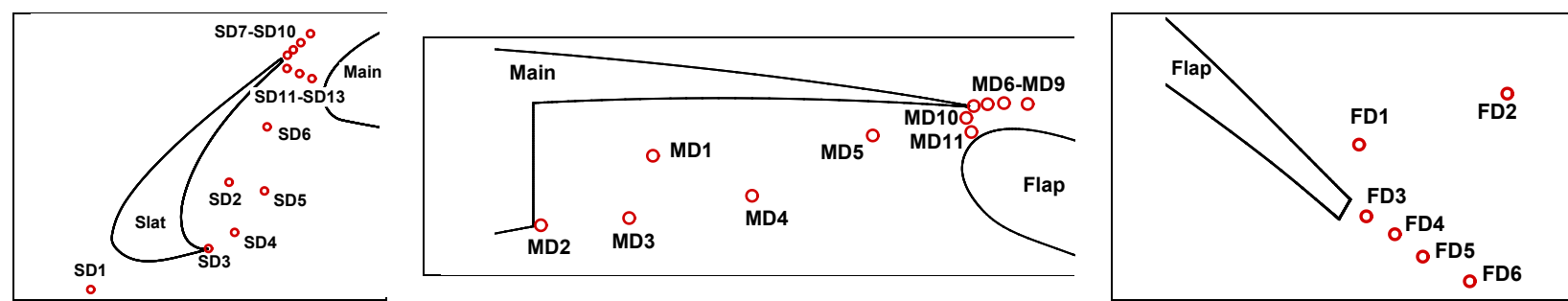

Fig. 37 Dynamic velocity probes.

Tab. 5 Coordinate of dynamic velocity probes.

\begin{tabular}{cccccc}
\hline \hline & Slat & & Main & Flap \\
\hline SD1 & $(-0.044614,-0.060982)$ & MD1 & $(0.341888,0.005040)$ & FD1 & $(0.517848,-0.057314)$ \\
SD2 & $(-0.006206,-0.031227)$ & MD2 & $(0.321419,-0.007660)$ & FD2 & $(0.542104,-0.051880)$ \\
SD3 & $(-0.011921,-0.049611)$ & MD3 & $(0.337548,-0.006344)$ & FD3 & $(0.517330,-0.066519)$ \\
SD4 & $(-0.004663,-0.045135)$ & MD4 & $(0.360006,-0.002272)$ & FD4 & $(0.520882,-0.068416)$ \\
SD5 & $(0.003615,-0.033636)$ & MD5 & $(0.382061,0.008750)$ & FD5 & $(0.525307,-0.071020)$ \\
SD6 & $(0.004347,-0.015865)$ & MD6 & $(0.400517,0.014129)$ & FD6 & $(0.531690,-0.073986)$ \\
SD7 & $(0.009984,0.003998)$ & MD7 & $(0.403050,0.014466)$ & & \\
SD8 & $(0.011624,0.005513)$ & MD8 & $(0.406037,0.014669)$ & & \\
SD9 & $(0.013701,0.007480)$ & MD9 & $(0.410366,0.014504)$ & & \\
SD10 & $(0.016395,0.009970)$ & MD10 & $(0.399148,0.011960)$ & & \\
SD11 & $(0.009870,0.000331)$ & MD11 & $(0.400082,0.009380)$ & & \\
SD12 & $(0.013362,-0.001104)$ & & & & \\
SD13 & $(0.016811,-0.002479)$ & & & & \\
\hline \hline
\end{tabular}




\section{References}

[1] Sadeghian, M, Gorji-Bandpy M., "Investigation All Types of Aircraft Noises: Review Paper" American Journal of Science, Engineering and Technology. Vol. 5, No. 1, 2020, pp. 33-41. doi: 10.11648/j.ajset.20200501.14.

[2] Jeremy Astley, R. Can Technology Deliver Acceptable Levels of Aircraft Noise? 2014.

[3] Huff, D. L. Noise Reduction Technologies for Turbofan Engines. 2006.

[4] Appelbaum, J., Duda, B. M., Fares, E., and Khorrami, M. R. Airframe Noise Simulations of a Full-Scale Aircraft. 2018.

[5] Dobrzynski, W. “Almost 40 Years of Airframe Noise Research: What Did We Achieve?” Journal of Aircraft, Vol. 47, No. 2, 2010, pp. 353-367. https://doi.org/10.2514/1.44457.

[6] Khorrami, M. R., and Fares, E. Simulation-Based Airframe Noise Prediction of a Full-Scale, Full Aircraft. 2016.

[7] Choudhari, M., and Lockard, D. "Simulations \& Measurements of Airframe Noise: A BANC Workshops Perspective." Nato Otan, 2017.

[8] Wilsby, O. L., and Sandberg, R. D. Data-Driven RANS Closures for Trailing Edge Noise Predictions. 2019.

[9] Casalino, D., Ribeiro, A. F. P., Fares, E., and Nölting, S. "Lattice-Boltzmann Aeroacoustic Analysis of the LAGOON Landing-Gear Configuration.” AIAA Journal, Vol. 52, No. 6, 2014, pp. $1232-1248$. https://doi.org/10.2514/1.J052365.

[10] Deck, S., and Laraufie, R. "Numerical Investigation of the Flow Dynamics Past a Three-Element Aerofoil." Journal of Fluid Mechanics, Vol. 732, 2013, pp. 401-444. https://doi.org/10.1017/jfm.2013.363.

[11] Fuchs, M., Fliessbach, L., Mockett, C., Kramer, F., Knacke, T., and Thiele, F. Aeroacoustic Prediction of a ThreeElement High-Lift Airfoil Using a Grey-Area Enhanced Des Model. 2019.

[12] Terracol, M., and Manoha, E. Wall-Resolved Large Eddy Simulation of a Highlift Airfoil: Detailed Flow Analysis and Noise Generation Study. 2014.

[13] Choudhari, M., Lockard, D., Khorrami, M., and Mineck, R. Slat Noise Simulations: Status and Challenges. $2011 .$.

[14] Choudhari M., Khorrami M., Lockard D., Slat Cove Noise: 30P30N 3-Element, Simplified High-Lift Configuration (Modified Slat), Guidelines for Category 7 of BANC-II Workshop, 2012, https://info.aiaa.org/tac/ASG/FDTC/DG/BECAN_files_BANCII.htm [retrieved 22 Sept. 2017].

[15] Choudhari, M., Lockard, D. P. et al., Assessment of Slat Noise Predictions for 30P30N High- Lift Configuration from Banc-III Workshop. 2015.

[16] Murayama, M., Nakakita, K., Yamamoto, K., Ura, H., Ito, Y., and Choudhari, M. M. Experimental Study of Slat Noise from 30P30N Three-Element High-Lift Airfoil in JAXA Hard-Wall Low-Speed Wind Tunnel. 2014.

[17] Murayama, M., Yokokawa, Y., Ura, H., Nakakita, K., Yamamoto, K., Ito, Y., Takaishi, T., Sakai, R., Shimoda, K., Kato, T., and Homma, T. Experimental Study of Slat Noise from 30P30N Three-Element High-Lift Airfoil in JAXA Kevlar-Wall Low-Speed Wind Tunnel. 2018.

[18] Pascioni, K. A., Cattafesta, L. N., and Choudhari, M. M. An Experimental Investigation of the 30P30N MultiElement High-Lift Airfoil. 2014.

[19] Pascioni, K. A., and Cattafesta, L. N. Aeroacoustic Measurements of Leading-Edge Slat Noise. 2016.

[20] Pascioni, K. A., and Cattafesta, L. N. “An Aeroacoustic Study of a Leading-Edge Slat: Beamforming and Far Field Estimation Using near Field Quantities." Journal of Sound and Vibration, Vol. 429, 2018, pp. $224-244$. https://doi.org/10.1016/j.jsv.2018.05.029.

[21] Pascioni, K. A., and Cattafesta, L. N. "Unsteady Characteristics of a Slat-Cove Flow Field.” Physical Review Fluids, Vol. 3, No. 3, 2018, p. 034607. https://doi.org/10.1103/PhysRevFluids.3.034607.

[22] Liao, F., Ye, Z., and Zhang, L. "Extending Geometric Conservation Law to Cell-Centered Finite Difference Methods on Stationary Grids.” Journal of Computational Physics, Vol. 284, 2015, pp. $419-433$. https://doi.org/10.1016/i.jcp.2014.12.040. 
[23] Liao, F., and Ye, Z. "Extending Geometric Conservation Law to Cell-Centered Finite Difference Methods on Moving and Deforming Grids." Journal of Computational Physics, Vol. 303, 2015, pp. $212-221$. https://doi.org/10.1016/j.jcp.2015.09.032.

[24] Liao, F., and He, G. "High-Order Adapter Schemes for Cell-Centered Finite Difference Method." Journal of Computational Physics, Vol. 403, 2020, p. 109090. https://doi.org/10.1016/j.jcp.2019.109090.

[25] Shu, C.-W. "High Order Weighted Essentially Nonoscillatory Schemes for Convection Dominated Problems.” SIAM Review, Vol. 51, No. 1, 2009, pp. 82-126. https://doi.org/10.1137/070679065.

[26] Klopfer, G., Hung, C., Van der Wijngaart, R., and Onufer, J. A Diagonalized Diagonal Dominant Alternating Direction Implicit (D3ADI) Scheme and Subiteration Correction. 1998.

[27] Blazek, J. Computational Fluid Dynamics: Principles and Applications. 2005.

[28] Spalart, P. R. "Detached-Eddy Simulation.” Annual Review of Fluid Mechanics, Vol. 41, No. 1, 2009 , pp. $181-202$. https://doi.org/10.1146/annurev.fluid.010908.165130.

[29] Spalart, P. R., Deck, S., Shur, M. L., Squires, K. D., Strelets, M. K., and Travin, A. “A New Version of DetachedEddy Simulation, Resistant to Ambiguous Grid Densities." Theoretical and Computational Fluid Dynamics, Vol. 20, No. 3, 2006, pp. 181-195. https://doi.org/10.1007/s00162-006-0015-0.

[30] Chauvet, N., Deck, S., and Jacquin, L. "Zonal Detached Eddy Simulation of a Controlled Propulsive Jet." AIAA Journal, 2007. https://doi.org/10.2514/1.28562.

[31] Brès, G. A., Freed, D., Wessels, M., Noelting, S., and Pérot, F. "Flow and Noise Predictions for the Tandem Cylinder Aeroacoustic Benchmarka)." Physics of Fluids, Vol. 24, No. 3, 2012, p. 036101. https://doi.org/10.1063/1.3685102.

[32] Lockard, D. Summary of the Tandem Cylinder Solutions from the Benchmark Problems for Airframe Noise Computations-I Workshop. Proceedings of the 49th AIAA Aerospace Sciences Meeting, 2011, 2011-0353.

[33] Weinmann, M., Sandberg, R. D., and Doolan, C. "Tandem Cylinder Flow and Noise Predictions Using a Hybrid RANS/LES Approach." International Journal of Heat and Fluid Flow, Vol. 50, 2014, pp. $263-278$. https://doi.org/10.1016/j.ijheatfluidflow.2014.08.011.

[34] Wang, M., Fattah, R. J., Angland, D., and Zhang, X. High-Order Hybrid Cell-Centered Method for Computational Aeroacoustics, 21st AIAA/CEAS Aeroacoustics Conference, (2015) 2015-3279.

[35] Jenkins, L., Neuhart, D., McGinley, C., Khorrami, M., and Choudhari, M. Measurements of Unsteady Wake Interference Between Tandem Cylinders, 36th AIAA Fluid Dynamics Conference \& Exhibit, 2006.

[36] Pascioni, K. A., An Aeroacoustic Characterization of a Multi-Element High-Lift Airfoil, doctoral dissertation in Florida State University, 2017.

[37] Lockard, D. P., and Choudhari, M. M. The Variation of Slat Noise with Mach and Reynolds Numbers. 2011.

[38] Lockard, D. P., Choudhari, M. M., and Buning, P. G. Grid Sensitivity Study for Slat Noise Simulations. 2014 AIAA/CEAS Aeroacoustics Conference, AIAA AVIATION Forum, (2014) 2014-2627.

[39] Terracol, M., Manoha, E., Murayama, M., and Yamamoto, K. Aeroacoustic Calculations of the 30P30N High-Lift Airfoil Using Hybrid RANS/LES Methods: Modeling and Grid Resolution Effects. 2015.

[40] Ashton, N., West, A., and Mendonça, F. "Flow Dynamics Past a 30P30N Three-Element Airfoil Using Improved Delayed Detached-Eddy Simulation.” AIAA Journal, Vol. 54, No. 11, 2016, pp. 3657-3667. https://doi.org/10.2514/1.J054521.

[41] Zhang, Y., Chen, H., Wang, K., and Wang, M. "Aeroacoustic Prediction of a Multi-Element Airfoil Using WallModeled Large-Eddy Simulation.” AIAA Journal, Vol. 55, No. 12, 2017, pp. 4219-4233. https://doi.org/10.2514/1.J055853.

[42] Gao, J., Li, X., and Lin, D. Numerical Simulation of the Noise from the 30P30N Highlift Airfoil with Spectral Difference Method. 2017.

[43] Shi, J., Yan, H., and Wang, Z. J. Towards Direct Computation of Aeroacoustic Noise with the High-Order FR/CPR Method. 2018.

[44] Ishida, T. Aerodynamic Simulations of a High-Lift Configuration by Lattice Boltzmann Method with BlockStructured Cartesian Grid. 2019. 
[45] Housman, J. A., Stich, G.-D., Kocheemoolayil, J. G., and Kiris, C. C. Predictions of Slat Noise from the 30P30N at High Angles of Attack Using Zonal Hybrid RANS-LES. 2019, 25th AIAA/CEAS Aeroacoustics Conference, (2019) 2019-2438.

[46] Sakai, R., Ishida, T., Murayama, M., Ito, Y., and Yamamoto, K. Slat Noise Simulation on Unstructured Grid with Reduced Dissipation Approach. 2019, 25th AIAA/CEAS Aeroacoustics Conference, (2019) 2019-2405.

[47] Ueno, Y., and Ochi, A. Airframe Noise Prediction Using Navier-Stokes Code with Cartesian and Boundary-Fitted Layer Meshes. 2019, 25th AIAA/CEAS Aeroacoustics Conference, (2019) 2019-2553.

[48] Kojima, Y., Ishida, T., Hashimoto, A., and Aoyama, T. Numerical Simulation of Unsteady Flow over a 30P30N Slat by Embedded-LES. 2020.

[49] https://cfdws.chofu.jaxa.jp/apc/grids/3element highlift_airfoil/.

[50] Terracol, M., Manoha, E., and Lemoine, B. "Investigation of the Unsteady Flow and Noise Generation in a Slat Cove." AIAA Journal, Vol. 54, No. 2, 2016, pp. 469-489. https://doi.org/10.2514/1.J053479.

[51] Van Dam, C. P. “The Aerodynamic Design of Multi-Element High-Lift Systems for Transport Airplanes.” Progress in Aerospace Sciences, Vol. 38, No. 2, 2002, pp. 101-144. https://doi.org/10.1016/S0376-0421(02)00002-7.

[52] Terracol, M., Manoha, E., and Lemoine, B. Investigation of the Unsteady Flow and Noise Sources Generation in a Slat Cove: Hybrid Zonal RANS/LES Simulation and Dedicated Experiment. 2011. 